\title{
REVIEW
}

\section{Molecular imaging and radionuclide therapy of pheochromocytoma and paraganglioma in the era of genomic characterization of disease subgroups}

\author{
David Taïeb1,*, Abhishek Jha2,*, Giorgio Treglia3,4,5 and Karel Pacak² \\ 1Department of Nuclear Medicine, La Timone University Hospital, CERIMED, Aix-Marseille University, Marseille, France \\ 2Section on Medical Neuroendocrinology, Eunice Kennedy Shriver National Institute of Child Health and Human Development, National Institutes of \\ Health, Bethesda, Maryland, USA \\ ${ }^{3}$ Clinic of Nuclear Medicine and PET/CT Center, Ente Ospedaliero Cantonale, Bellinzona, Switzerland \\ 4Department of Nuclear Medicine and Molecular Imaging, Lausanne University Hospital, Lausanne, Switzerland \\ ${ }_{5}^{5}$ Health Technology Assessment Unit, General Directorate, Ente Ospedaliero Cantonale, Bellinzona, Switzerland
}

Correspondence should be addressed to K Pacak: karel@mail.nih.gov

*(D Taïeb and A Jha contributed equally to this work)

\begin{abstract}
In recent years, advancement in genetics has profoundly helped to gain a more comprehensive molecular, pathogenic, and prognostic picture of pheochromocytomas and paragangliomas (PPGLs). Newly discovered molecular targets, particularly those that target cell membranes or signaling pathways have helped move nuclear medicine in the forefront of PPGL precision medicine. This is mainly based on the introduction and increasing experience of various PET radiopharmaceuticals across PPGL genotypes quickly followed by implementation of novel radiotherapies and revised imaging algorithms. Particularly, ${ }^{68} \mathrm{Ga}$-labeled-SSAs have shown excellent results in the diagnosis and staging of PPGLs and in selecting patients for PRRT as a potential alternative to 123/131|-MIBG theranostics. PRRT using 90Y/177LU-DOTA-SSAs has shown promise for treatment of PPGLs with improvement of clinical symptoms and/or disease control. However, more well-designed prospective studies are required to confirm these findings, in order to fully exploit PRRT's antitumoral properties to obtain the final FDA approval. Such an approval has recently been obtained for high-specific-activity ${ }^{131}$ I-MIBG for inoperable/metastatic PPGL. The increasing experience and encouraging preliminary results of these radiotherapeutic approaches in PPGLs now raises an important question of how to further integrate them into PPGL management (e.g. monotherapy or in combination with other systemic therapies), carefully taking into account the PPGLS locations, genotypes, and growth rate. Thus, targeted radionuclide therapy (TRT) should preferably be performed at specialized centers with an experienced interdisciplinary team. Future perspectives include the introduction of dosimetry and biomarkers for therapeutic responses for more individualized treatment plans, $\alpha$-emitting isotopes, and the combination of TRT with other systemic therapies.
\end{abstract}

\author{
Key Words \\ - pheochromocytoma \\ - paraganglioma \\ - PPGL \\ - succinate dehydrogenase \\ complex \\ - $S D H B$ \\ - 18F-FDOPA \\ - 68Ga-DOTATATE \\ - 18F-FDG \\ - 131I-MIBG \\ - peptide receptor \\ radionuclide therapy \\ - theranostics \\ - somatostatin receptor
}




\section{Learning points}

1) Know the molecular taxonomy of pheochromocytoma and/or paraganglioma (PPGL) and the relationship between various genotypes and imaging phenotypes;

2) Describe imaging features of $S D H x$-related PPGL;

3) Understand pathophysiologic basis of theranostics using iodine-123/131 (123/131I)-metaiodobenzylguanidine (123/131 I-MIBG) and peptide receptor radionuclide therapy $\left({ }^{177}\right.$ Lutetium $\left({ }^{177} \mathrm{Lu}\right)$ or ${ }^{90} \mathrm{Yttrium}\left({ }^{90} \mathrm{Y}\right)$-DOTA somatostatin analogs) and know the results of clinical studies;

4) Understand the main areas of improvement of radiotherapeutics in the management of PPGL.

\section{Key messages}

1) Positron emission tomography imaging using gallium-68 ( $\left.{ }^{68} \mathrm{Ga}\right)$-labeled somatostatin receptor analogs (SSAs) is the most sensitive approach for PPGL localization and can select patients for peptide receptor radionuclide therapy (PRRT).

2) Approximately $234 \quad(n=166,71 \%$ patients with progressive disease) PPGL patients have been treated on compassionate grounds with PRRT and promising results have been reported mostly in the setting of retrospective small case reports or case series.

3) Following a multicentric phase II study, high-specificactivity iodine-131 (131I)-MIBG (Azedra ${ }^{\circledR}$ ) has received FDA approval for metastatic or locally aggressive PPGL.

4) Potential indications of radiotherapeutics in PPGL include inoperable PPGL with progressive and/or symptomatic metastatic PPGL.

5) The future perspectives include the introduction of dosimetry and biomarkers for therapeutic responses for more individualized treatment plans, $\alpha$-emitting isotopes, and combination of targeted radionuclide therapy with other forms of treatment, including immunotherapy.

\section{Current classification of PPGL}

Pheochromocytomas (PHEOs) and paragangliomas (PGLs, together called PPGLs) are neuroendocrine tumors (NETs) arising from neural crest-derived adrenal or extra-adrenal paraganglia, respectively. Around $5-10 \%$ of solitary pheochromocytomas are hereditary, whereas tumor multiplicity or extra-adrenal tumors are related to currently known germline mutations in $40-70 \%$ of patients.
These are now recognized to be caused by at least 20 susceptibility genes (Dahia 2014, Crona et al. 2017, Fishbein et al. 2017, Jochmanova \& Pacak 2018). A majority of PPGLs can be described as carrying either germline or somatic mutations. Depending on their transcription profile, recent data obtained from The Cancer Genome Atlas (TCGA) has divided PPGL into three clinically relevant clusters:

1. Pseudohypoxia group (cluster 1) is divided into at least two subgroups: the first, tricarboxylic acid (TCA) cycle-related germline mutations mainly in succinate dehydrogenase subunits $(S D H x)$ and fumarate hydratase $(F H)$. The second subgroup includes von Hippel-Lindau tumor suppressor (VHL)and endothelial PAS domain protein 1 (EPAS1)-related somatic and germline mutations.

2. Kinase signaling group (cluster 2) consists of germline or somatic mutations in ret proto-oncogene (RET), neurofibromin 1 (NF1), transmembrane protein 127 (TMEM127), MYC-associated factor X (MAX), and HRas proto-oncogene (HRAS).

3. Wnt signaling group (cluster 3) includes newly recognized somatic mutations in cold shock domain containing E1 (CSDE1), as well as somatic gene fusions affecting mastermind-like transcriptional coactivator 3 (MAML3).

Most importantly from a clinical standpoint, some correlations exist between the gene(s) involved and tumor's anatomic location:

a) PHEO: RET, VHL, SDHX, NF1, MAX, TMEM127, HRAS.

b) Extra-adrenal retroperitoneal PGLs: $S D H x, F H, V H L$ (rare), prolyl hydroxylase 1 and 2 (PHD1/2) and EPAS1/hypoxia-inducible factor 2 alpha (HIF2A).

c) Head and neck PGL (HNPGL): SDHx.

Major predictors for hereditary PPGL include a family and personal history of PPGL, inherited in an autosomal dominant manner but with varying penetrance, characteristic syndromic presentation, young age at diagnosis, multifocality, unusual location/s (e.g. heart, urinary bladder), and/or tumor recurrence, particularly in the adrenal gland (Neumann et al. 2009, 2018, Welander et al. 2011, Jafri et al. 2013, Benn et al. 2015, Favier et al. 2015). Renal cell carcinoma (RCC), gastrointestinal stromal tumor (GIST), pituitary adenoma, and rarely, pulmonary chondroma, neuroblastoma, and neuroendocrine neoplasms (usually carcinoid) can also be related to SDHx and rarely to other PPGL susceptibility gene mutations (Pasini et al. 2008, Papathomas et al. 2014, 
Casey et al. 2017). Other clinical manifestations can also be suggestive of particular gene mutations. For example, prior medullary thyroid cancer (MTC) for RET, café-au-lait spots/neurofibromas for NF1, RCC/hemangioblastomas/ pancreatic tumors for $V H L$, congenital polycythemia and duodenal somatostatinoma for EPAS1/HIF2A (Zhuang et al. 2012), and RCC/leiomyomas for $F H$ (Castro-Vega et al. 2014).

Furthermore, PPGL with an underlying $S D H B$ mutation are associated with a higher risk of aggressive behavior than other hereditary PPGLs leading ultimately to death, particularly due to development of metastatic disease. The risk of metastasis in SDHB-related tumors has been estimated to range from 30 to $80 \%$ (GimenezRoqueplo et al. 2003, Neumann et al. 2004, Amar et al. 2005, 2007, Benn et al. 2006, Brouwers et al. 2006, King et al. 2011, Turkova et al. 2016, Hamidi et al. 2017). In addition to impacting the distribution of disease, the genomically distinct subgroups of PPGLs have different patterns of catecholamine secretion and the expression of cell membrane receptors and transporters, which impact their imaging phenotype, particularly the uptake of catecholamines or their precursors (Eisenhofer et al. 1999, 2011, Fonte et al. 2012).

\section{${ }^{68}$ Ga-DOTA-SSAs in PPGL and imaging phenotypes across PPGL subgroups}

There are diverse radionuclide imaging techniques available for the diagnosis, staging and follow-up of PPGLs. Beyond their ability to specifically detect and localize PPGLs, these imaging approaches variably characterize these tumors at cellular and molecular levels. More recently, gallium-68 $\left({ }^{68} \mathrm{Ga}\right)$-labeled somatostatin receptor analogs (SSAs) positron emission tomography-computed tomography (PET/CT) is being increasingly performed to detect PPGLs and assess their somatostatin receptor (SSTR) expression which is paramount for PRRT in inoperable or locally aggressive/metastatic disease (Nolting et al. 2019, Taieb et al. 2019).

In a recent systematic review and meta-analysis, the pooled PPGL detection rate of ${ }^{8} \mathrm{Ga}$-DOTA-SSA PET/CT in patients with unknown genetic status was 93\% (95\% confidence interval (CI) 91-95\%), which was significantly higher than that of $18 \mathrm{~F}$-fluorodihydroxyphenylalanine (18F-FDOPA) PET/CT (80\% (95\% CI 69-88\%)), ${ }^{18} \mathrm{~F}$-fluorodeoxyglucose (18F-FDG) PET/CT (74\% (95\% CI 46-91\%)), and 123/131-MIBG scintigraphy (38\% (95\% CI 20-59\%), $P<0.001$ for all) (Han et al. 2019).
This meta-analysis demonstrated the intrinsic value of ${ }^{68} \mathrm{Ga}$-DOTA-SSA PET/CT in the detection of PPGL even when a physician is not aided by the knowledge of genetic status of the patient. On the contrary, in another meta-analysis (Kan et al. 2018), ${ }^{68} \mathrm{Ga}$-DOTA-SSA PET/CT detected more PPGL lesions with germline mutations (did not specify the exact mutation) than ${ }^{18}$ F-FDG PET/CT (97 vs 79\%); however, only four studies (pooled patients $=79$ ) included in this meta-analysis used both radiopharmaceuticals (Janssen et al. 2015, 2016a, Tan et al. 2015, Chang et al. 2016).

In a recent non-comparative study from the Royal North Shore Hospital in Australia, ${ }^{68} \mathrm{Ga}$-DOTATATE PET/CT was evaluated for initial staging $(n=28)$ and restaging ( $n=18$, including eight metastatic cases) for PHEOs and for initial staging $(n=8)$ and restaging $(n=18$, including four metastatic cases) for PGLs. Overall, ${ }^{68} \mathrm{Ga}$-DOTATATE PET/CT had a sensitivity of $84 \%$ for PHEO (21/24) and 100\% (7/7) for PGL (Gild et al. 2018). Further, ${ }^{68} \mathrm{Ga}$-DOTATATE PET/CT resulted in change of management in 50\% PHEOs (23/46) and 44\% (12/27) PGLs.

In a retrospective mixed cohort study in 12 patients of neural crest tumors ( $n=11$, PPGL; $n=1$, medullary thyroid carcinoma), per patient and per lesion detection rates of ${ }^{68} \mathrm{Ga}$-DOTATATE PET/CT was found to be superior to 123 I-MIBG SPECT/CT $(83 \%(10 / 12)$ vs and not vs $42 \%(5 / 12)$ and $96.7 \%(29 / 30)$ vs and not vs $23.3 \%$ (7/30)), respectively (Naji et al. 2011). Further, three of four $S D H B$ patients were detected by ${ }^{68} \mathrm{Ga}$-DOTATATE PET/CT, whereas 123I-MIBG SPECT/CT was negative in all SDHB patients (Naji et al. 2011). ${ }^{68} \mathrm{Ga}$-DOTATATE performed superior to ${ }^{18} \mathrm{~F}-\mathrm{FDG}$ PET/CT (96.2 vs $91.4 \%$ ) in a mixed cohort of 23 ( $n=10$ SDHx mutated) patients and $123 / 124$ I-MIBG detected very few lesions $(30.4 \%$ in 7 patients) (Chang et al. 2016). Also, per lesion detection rate of ${ }^{68} \mathrm{Ga}$-DOTATATE PET/CT was superior to ${ }^{123} \mathrm{I}$-MIBG scintigraphy $(100 \%, 29 / 27$ vs and not vs $6.9 \%, 2 / 27)$ in ten extra-adrenal PGL patients (Kroiss et al. 2015).

The use of ${ }^{68} \mathrm{Ga}$-DOTA-SSA has shown excellent results in localizing PHEOs or PGLs, including primary and/or metastatic PPGLs (Naji et al. 2011, Sharma et al. 2013, 2014, 2015, Hofman et al. 2015, Kroiss et al. 2015).

Head-to-head comparison between ${ }^{68} \mathrm{Ga}$-DOTA-SSAs and ${ }^{18} \mathrm{~F}-\mathrm{FDOPA}$ PET/CT has been performed in only seven studies: one retrospective study from Innsbruck Medical University ( ${ }^{68} \mathrm{Ga}$-DOTATOC in 20 patients with unknown genetic background) (Kroiss et al. 2013), five prospective studies from the National Institutes of Health $(\mathrm{NIH}){ }^{68} \mathrm{Ga}$-DOTATATE in 17 patients with metastatic $S D H B-, 22$ patients with metastatic sporadic, 
20 patients with HNPGLs, 14 patients with polycythemia and PGL syndromes, and 23 patients with SDHDrelated PPGL, respectively) (Janssen et al. 2015, 2016a,b, 2017, Jha et al. 2018a) and one prospective study from La Timone University Hospital ( ${ }^{68} \mathrm{Ga}$-DOTATATE in 30 patients) (Archier et al. 2016) (Table 1). The separate data for apparently sporadic PHEO could be extracted from one study (Archier et al. 2016) for ten patients in whom 18F-FDOPA PET/CT showed better patient-based and lesion-based detection rates than ${ }^{68} \mathrm{Ga}-\mathrm{DOTA}-\mathrm{SSA}$ PET/CT (100 vs 90\% and 94 vs 81\%, respectively). ${ }^{68} \mathrm{Ga}$-DOTA-SSA PET/CT might be inferior to ${ }^{18} \mathrm{~F}$-FDOPA PET/CT in the detection of small PHEOs (Archier et al. 2016). However, the preliminary study from NIH in apparently sporadic PHEOs shows that ${ }^{68} \mathrm{Ga}$-DOTA-SSA performs similar to ${ }^{18} \mathrm{~F}-\mathrm{FDOPA}$ PET/CT (Jha et al. 2019b).

The elevated clinical value of ${ }^{68} \mathrm{Ga}$-DOTATATE was also observed in the pediatric population with $S D H x$ mutation (Jha et al. 2018b). ${ }^{68} \mathrm{Ga}$-DOTA-SSA PET/CT can therefore, be recommended for diagnosis, staging, and follow-up imaging of PPGL with underlying SDHx mutations (Janssen et al. 2015, Jha et al. 2018a,b, 2019a). Further, it is suggestive that ${ }^{68} \mathrm{Ga}$-DOTA-SSA PET/CT is the most sensitive tool in the detection of HNPGLs, especially SDHD-related tumors, which may be very small in size and/or fail to sufficiently concentrate ${ }^{18}$ F-FDOPA (Fig. 1). One would consider that detection of additional sites in patients with diffuse metastatic disease is of limited interest. However, many of these lesions are not well characterized (small nodes) or even detected (bone marrow metastases) by anatomical imaging. The suboptimal value of conventional imaging poses a diagnostic challenge in the evaluation of metastatic PPGL patients. Although assessment of RECIST criteria by cross-sectional imaging is currently the referential method, incorporation of PET using SSA as part of a surveillance program seems prudent for accurate evaluation (Kong et al. 2019). Also, functional imaging can localize subcentimetric new lesions which take time to appear on cross-sectional imaging, and hence, can aid in change of treatment earlier in case of progression. Further, in biochemically negative patients, the tumor load can be adequately determined by the functional imaging.

Follow-up imaging varies from patient to patient. The more intensive follow-up imaging is required in metastatic patients or patients who are at high risk to develop metastases. Such high risk-factors have been identified as SDHB, SDHA germline mutations, ATRX mutation, male sex, patient with large primary tumors (various studies have identified that from $>4.5-5 \mathrm{~cm}$ to
$>10 \mathrm{~cm}$ ), noradrenergic or dopaminergic biochemical phenotype, older age at primary tumor diagnosis (>40-50 years), and high proliferative index (AyalaRamirez et al. 2011, King et al. 2011, Schovanek et al. 2014, Plouin et al. 2016, Hamidi et al. 2017, Jha et al. 2019a, Crona et al. 2019, Hescot et al. 2019, Mei et al. 2019). These patients should be followed up indefinitely involving either whole-body CT/MRI and/or functional imaging. All of these patients should receive whole-body CT/MRI at baseline along with whole-body functional PET/CT imaging per algorithm for the staging. Depending upon the severity of disease and therapy (chemotherapy, cold SSA, PRRT), the optimal length of follow-up imaging in these patients should be decided. The patients with high metastatic load (lungs and liver metastases) and/or progressive disease should be imaged every 6-8 months, whereas the metastatic patients who are stable or are under wait-and-watch protocol should be imaged every 12 months. At our institution, every patient gets whole-body anatomic and functional follow-up imaging. The information from anatomic and functional imaging along with biochemical results and clinical information is considered during evaluation regarding disease progression. The patients with only primary tumors, follow-up anatomic imaging should occur after 3 months of surgical resection to evaluate residual and/or recurrent tumor. Following no evidence of recurrence/residual disease, repeat follow-up imaging should take every year for first 5 years and then if the patient is free of disease, it can be increased to every 3 years; however, patients should receive yearly biochemical evaluation. The response evaluation using RECIST, PERCIST, and EORTC has been described in solid tumors. However, they have not been validated in PPGL especially PERCIST or EORTC using ${ }^{68} \mathrm{Ga}$-DOTA-SSA PET/CT. Further studies in this regard would be warranted. Moreover, metabolic tissue burden can have a significant effect on SUV measurements for PET imaging. So, when using PET response, this effect should be mitigated by normalizing uptake values to a reference tissue (blood pool or liver) (Viglianti et al. 2018). Further, when ${ }^{68} \mathrm{Ga}$-DOTA-SSA PET/CT is used to evaluate longacting SSA therapy, it must be kept in mind that in most cases long-acting SSA therapy increases intensity of uptake (both SUVmax and normalized to liver) within metastases, and hence, the results should be interpreted accordingly (Cherk et al. 2018).

The rare mutations EPAS1 (HIF2A), PHDs, MAX, and $F H$ remain an exception among susceptibility genes since they lead to PPGLs that concentrate less 


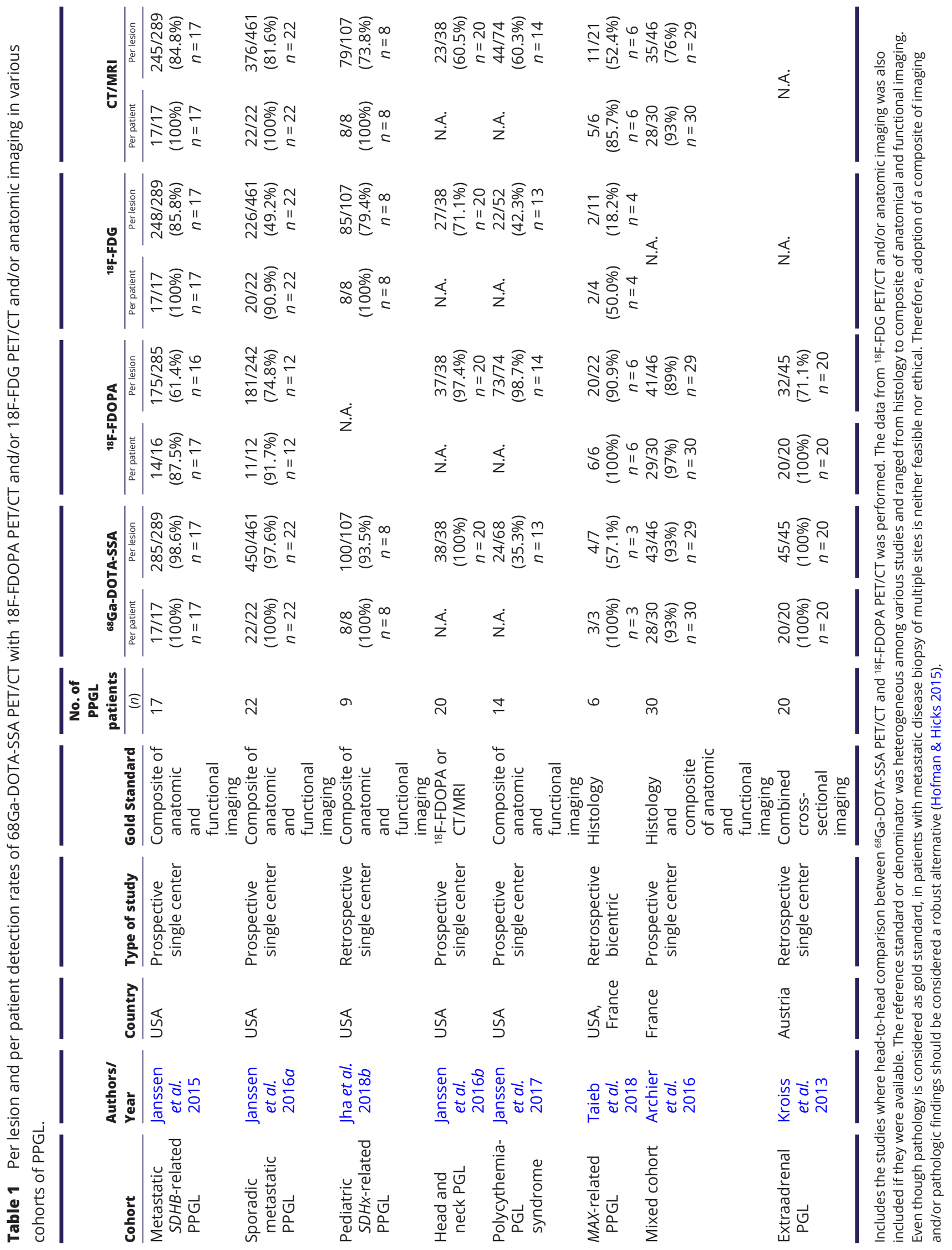




\title{
B
}

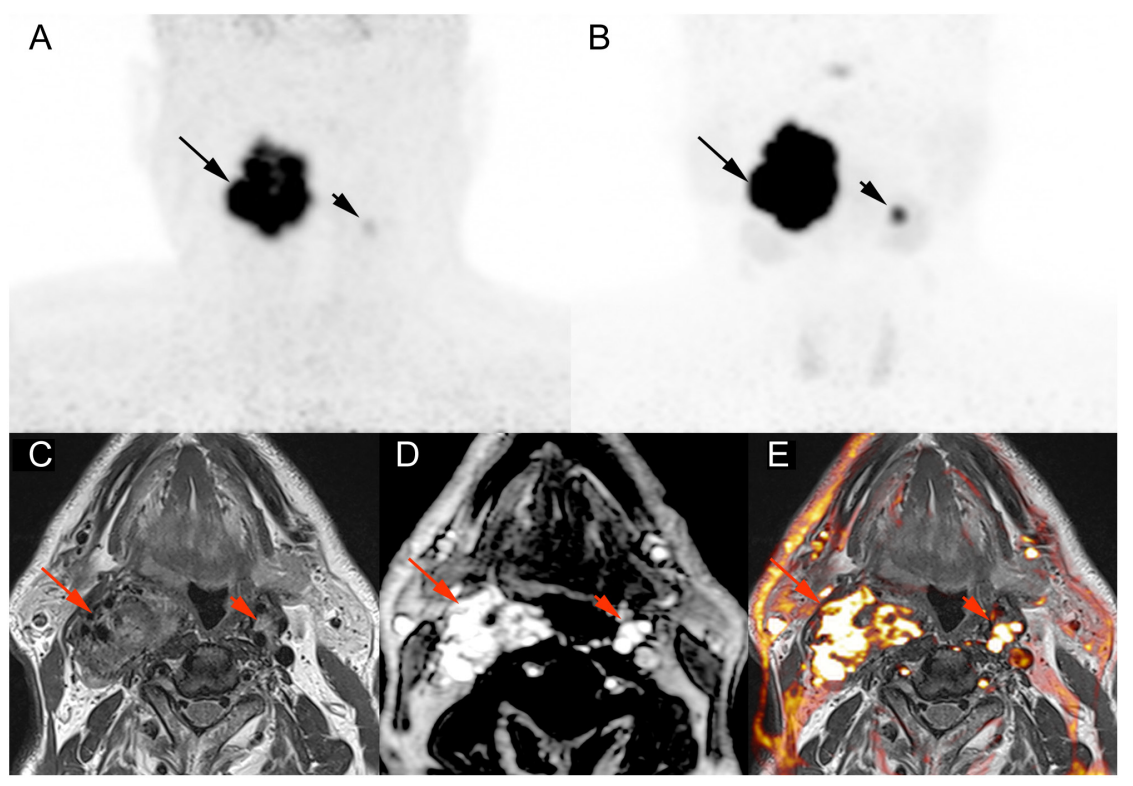

\begin{abstract}
Figure 1
Multifocal SDHD-related vagal PGLs (VPGLs). (A) Craniocervical ${ }^{18 F-F D O P A ~ P E T ~ i m a g e ~(m a x i m u m ~}$ intensity projection: MIP) showing the two VPGLs (arrows). (B) Craniocervical ${ }^{68} \mathrm{Ga}$-DOTATATE image (MIP) showing two VPs (arrows) with higher tumor uptake compared to ${ }^{18 F-F D O P A ~ P E T . ~(C, ~ D, ~ E) ~}$ Magnetic resonance (MR) images (C) T2-weighted image; (D) T1-weighted dynamic contrast enhanced (DCE) image; (E) T1-weighted DCE image/T2 weighted image fusion image) showing both VPGLs with arterial enhancement pattern on magnetic resonance angiogram images.
\end{abstract}

${ }^{68} \mathrm{Ga}$-DOTA-SSA in contrast to SDHx-related and other PPGLs; however, findings need to be confirmed in a larger group of patients with $F H$ mutation (Darr et al. 2016, Nambuba et al. 2016, Janssen et al. 2017, Taieb et al. 2018). The mechanism for this phenotype is currently largely unexplained. Von Hippel-Lindau syndrome, which is another pseudohypoxia-related disorder but with normal succinate levels, presents with a high ${ }^{18}$ F-FDOPA uptake in contrast to ${ }^{18}$ F-FDG uptake that varies from low to high. In the kinase signaling group, ${ }^{18}$ F-FDOPA is probably the best radiopharmaceutical due to its high tumor uptake together with a limited uptake in the remaining (unaffected) adrenal gland (Taieb et al. 2018). However, data are still limited regarding the value of ${ }^{68} \mathrm{Ga}$-DOTA-SSA PET/CT in these patients including MEN2 syndrome patients where head-to-head comparison with 18F-FDOPA has to be performed to provide any firm clinical conclusion and recommendation (Figs 2 and 3). However, for MEN2 patients with positive biochemistry and CT/MRI showing unilateral or bilateral adrenal tumors, functional imaging is not needed.

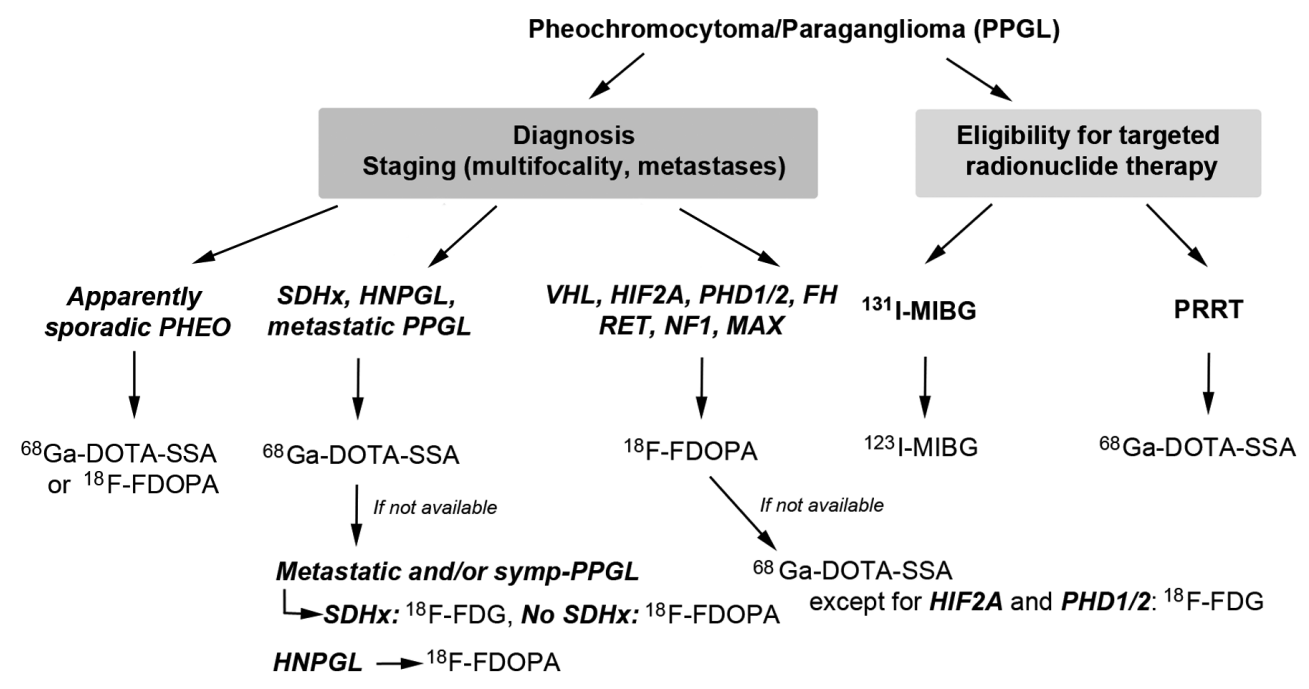

Figure 2

Proposed clinical algorithm for nuclear imaging investigations of pheochromocytoma/paraganglioma patients according to genotype. The algorithm has been proposed for patients with suspected or confirmed PPGL in order to help toward the appropriate use of PET radiopharmaceuticals across PPGL subtypes. It may suffer from potential limitation of reported small number of cases. The optimal follow-up algorithm for non-proband SDHx-associated PPGLs remains to be determined but mostly relies on annual biochemical screening and CT/MRI at regular intervals. 

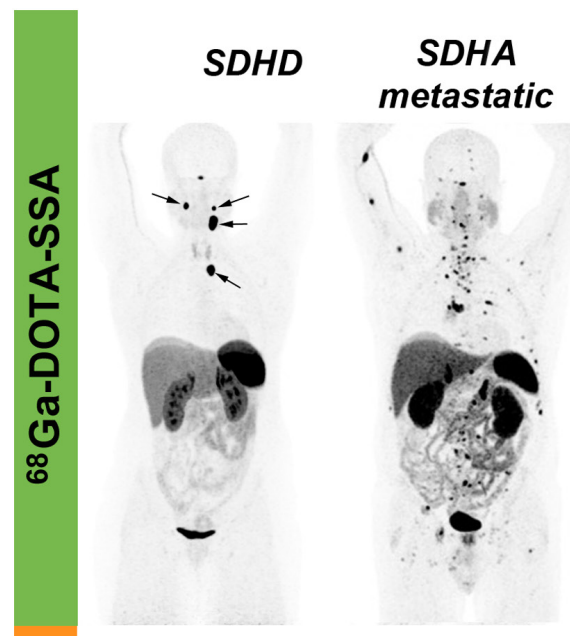

VHL

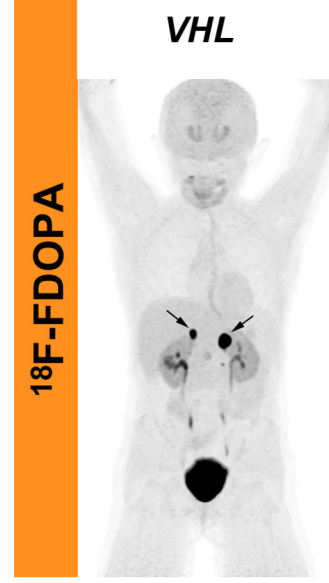

HIF2A

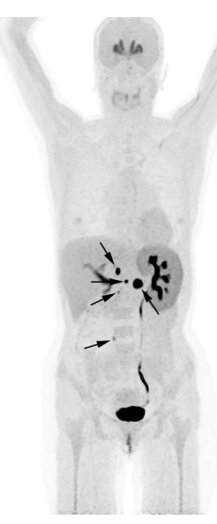

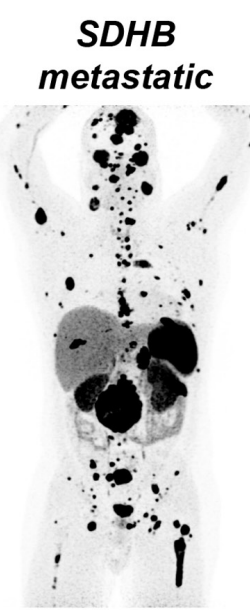

RET

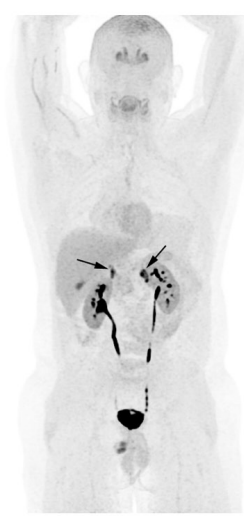

As proposed in Fig. 2, when genetic status is unknown and in the absence of tumor multifocality or familial trait, ${ }^{68} \mathrm{Ga}$-DOTA-SSA PET/CT should be proposed as first-line imaging modality in HNPGL, sporadic PHEO, extra-adrenal PGL, and metastatic cases (Kroiss et al. 2013, Janssen et al. 2016a,b, Jha et al. 2018a,b, 2019a,b, Han et al. 2019). For those associated with mutations in NF1/RET/MAX, 18F-FDOPA PET/CT should be recommended first due to the optimal tumor-to-adrenal uptake ratio that facilitates their detection. However, since ${ }^{18} \mathrm{~F}-\mathrm{FDOPA}$ is not widely available, this could be replaced by ${ }^{68} \mathrm{Ga}$-DOTA-SSA or 123I-MIBG depending upon specific technical or legislative limitations across countries. ${ }^{123}$ I-MIBG is also needed to select potential patients with ${ }^{131}$ I-MIBG therapy (Fig. 2). Many of these reports are based on extremely rare cohorts (HIF2A, PHD1/2, FH, MAX, pediatric SDHx); therefore, these studies have extremely small number of patients. However, due to the lack of information on functional imaging modalities available in the scientific literature, it becomes important to report findings obtained from even small study cohort. Also, the reference standard or

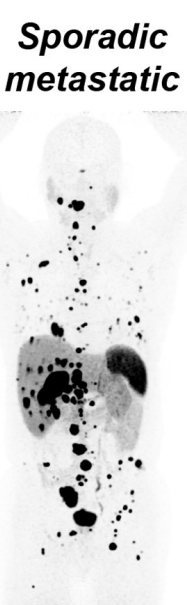

MAX

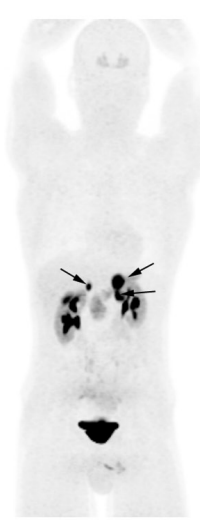

Figure 3

First-choice PET radiopharmaceuticals across genotypes.

denominator was heterogeneous among various studies and ranged from histology to composite of anatomical and functional imaging. Even though pathology is considered as gold standard, in patients with metastatic disease, biopsy of multiple sites is neither feasible nor ethical. Therefore, adoption of a composite of imaging and/or pathologic findings should be considered a robust alternative (Hofman \& Hicks 2015).

More recently, new radiopharmaceuticals have been proposed (124I-MIBG, $\left.{ }^{18} \mathrm{~F}-\mathrm{MFBG}\right)$ for targeting norepinephrine transporter and appear superior to 123I-MIBG (Hartung-Knemeyer et al. 2012, Cistaro et al. 2015, Pandit-Taskar et al. 2018).

\section{Theranostics}

Personalized (precision) medicine has already made its mark and has the potential to enhance patient management. It consists in adapting healthcare strategies tailored to individual and disease characteristics. 
Beyond the expected clinical benefits of personalized medicine, theranostics could also have a significant positive economic effect (Taieb et al. 2016). Nuclear medicine has a central role in personalized medicine via theranostic approaches. The term 'theranostics' was coined by John Funkhouser which encapsulates the integration of diagnostic and therapeutic functions within the same pharmaceutical platform (a theranostics pair) (Kelkar \& Reineke 2011). Therefore, results derived from an imaging study based on a compound labeled with a diagnostic radionuclide can precisely determine whether an individual patient is likely to benefit from a specific treatment using the same related compound labeled with a therapeutic radionuclide. Initially, 123/131I-MIBG targeting norepinephrine transporter system and more recently ${ }^{68} \mathrm{Ga} /{ }^{90} \mathrm{Y} /{ }^{177} \mathrm{Lu}-\mathrm{DOTA}-\mathrm{SSA}$ analogs targeting peptide (somatostatin) receptors have been introduced as theranostic agents for PPGLs (Nolting et al. 2019).

\section{1|-MIBG theranostics}

In advanced PPGLs, ${ }^{131}$ I-MIBG treatment is still recommended for 123I-MIBG-positive patients. Conventional ${ }^{123}$ I-MIBG scintigraphy is first used to assess these tumors for the presence of cell membrane norepinephrine transporter system. However, the majority of studies on ${ }^{131}$ I-MIBG theranostics are retrospective, heterogeneous in terms of baseline patient characteristics, and use of treatment protocols. A large systematic review and meta-analysis of 17 studies comprising 243 patients on ${ }^{131}$ I-MIBG published between 1984 and 2012 (follow-up duration, 24-62 months) showed a complete response, partial response, and stable disease in 3\% (95\% CI, 6-15\%), 27\% (95\% CI, 19-37\%), and 52\% (95\% CI, $41-62 \%$ ) of pooled patients, respectively (van Hulsteijn et al. 2014).

One of the main drawbacks of conventional MIBG preparations is that more than $99 \%$ of the MIBG molecules are not labeled with ${ }^{131} \mathrm{I}$, therefore, possibly competing for norepinephrine transporter-binding sites and disrupting norepinephrine reuptake mechanism. This may lead to decreased absorbed dose and possibly increased side effects especially with high-dose administrations (>12 mCi/kg) (Gonias et al. 2009, Carrasquillo et al. 2016). Hematotoxicity was the most significant toxicity especially thrombocytopenia (Carrasquillo et al. 2016). Low-dose administrations $(149 \mathrm{mCi})$ were well tolerated; however, following high-dose administrations ( $>12 \mathrm{mCi} / \mathrm{kg})$, grade 3 or 4 thrombocytopenia andleukopenia was observed in $83-87 \%$ of patients, requiring platelet transfusion and growth factors $(>12 \mathrm{mCi} / \mathrm{kg}$ ) (Gonias et al. 2009, Carrasquillo et al. 2016). Myelodysplastic syndrome (MDS) and acute leukemias (ALs) have been reported in patients treated with large amounts of ${ }^{131}$ I-MIBG and chemotherapy (Carrasquillo et al. 2016) with a $4 \%$ of MDS incidence with high-dose administrations (Gonias et al. 2009). Other reported toxicities are hypothyroidism (11-20\%) even with low-dose administrations, hypogonadism with both low-dose and high-dose administrations, acute respiratory distress syndrome and bronchiolitis obliterans and hypertension with high-dose administrations only (Carrasquillo et al. 2016). Hypertensive crises (despite blocking reuptake of norepinephrine), renal failure, and hepatotoxicity were rarely reported (Carrasquillo et al. 2016). More recently, high-specific-activity (HSA) ${ }^{131}$ I-MIBG that consists almost entirely of ${ }^{131}$ I-MIBG (HSA, $\quad 2500 \mathrm{mCi} / \mathrm{mg}, \quad 92,500 \mathrm{MBq} / \mathrm{mg}$ ) has been developed (Pryma et al. 2019). In a recent multicentric phase II study by Pryma et al., 68 and 50 PPGL patients received one or two therapeutic doses of HSA ${ }^{131}$ I-MIBG, respectively (Pryma et al. 2019). All treated patients had disease progression on prior therapy or were ineligible for chemotherapy or other therapies. HSA 131I-MIBG was administrated at $0.3 \mathrm{GBq} / \mathrm{kg}$. Of the 68 patients who received at least one therapeutic dose of HSA ${ }^{131}$ I-MIBG, 17 (25\%; 95\% CI, 16-37\%) had a durable reduction in baseline antihypertensive medication use. Most patients (92\% among the 64 patients) with evaluable disease experienced partial response $(23.4 \%, 15 / 64)$ or stable disease $(68.7 \%, 44 / 64)$. The median overall survival (OS) was 37 months (95\% CI, 31-49 months); however, it was 44 months (95\% CI, 32-60 months) for patients who received two therapeutic doses of HSA ${ }^{131}$ I-MIBG versus 18 months (95\% CI, 4-31 months) for those who received one dose. Prolonged myelosuppression was the most common cause for patients not receiving the second therapeutic dose. Interestingly, median survival rates for patients with or without lung and/or liver metastases was similar (43 vs 41 months). No patients had drug-related acute hypertensive events. Sixty-one patients (90\%) experienced hematologic adverse events, which were grade 3 or 4 adverse events or other severe adverse events in 49 (72\%) of these patients. Seventeen patients (25\%) required hematological supportive care. Treatment-related serious adverse events included hematologic toxicities (13 patients, 19\%), pulmonary embolism in two patients (3\%), MDS in three patients (4\%). Secondary malignancies included acute myeloid leukemia and acute lymphocytic leukemia in one patient each. 
HSA ${ }^{131}$ I-MIBG has recently received FDA approval. Although effective, the use of HSA 131I-MIBG is associated with higher rate of hematologic toxicity which possibly got amplified due to previous cytotoxic therapies together with some individual susceptibilities. However, these side effects should be well considered before recommending it to patients and they need to be informed about the risks when being consented for such a therapeutic option. 123I-MIBG scintigraphy should be used as a theranostic radiopharmaceutical for determining if a patient is eligible for ${ }^{131}$ I-MIBG therapy and patient-specific dosimetry should be performed to optimize therapy. Although not widely available, the PET equivalent, ${ }^{124} \mathrm{I}-\mathrm{MIBG}$, has significant advantages in terms of spatial resolution and its ability to quantify uptake for more reliable dosimetry calculations that would be preferable when HSA ${ }^{131}$ I-MIBG is considered as a therapeutic option.

\section{PRRT using radiolabeled-somatostatin analogs}

\section{PPRT in NET (PPGL excluded)}

PRRT is now a well-established treatment option for well-differentiated advanced NETs. The principle of SSTR-directed PRRT is to selectively deliver radiation dose to tumors that overexpress SSTRs with preservation of healthy surrounding tissues. PRRT is based on the administration of SSA labeled with a therapeutic isotope (e.g. ${ }^{177}$ Lutetium $\left({ }^{177} \mathrm{Lu}\right),{ }^{90}$ Yttrium $\left({ }^{90} \mathrm{Y}\right)$ ). Selection of good candidates is based on the use of a companion diagnostic agent corresponding to the same SSA labeled with ${ }^{111}$ Indium or ${ }^{68} \mathrm{Ga}$, which is now preferred for molecular imaging of PPGL. PRRT with ${ }^{177} \mathrm{Lu}$ was pioneered by the Erasmus group who demonstrated highly favorable results in a large cohort of NET patients. Despite the impressive results achieved using these approaches, this therapy was initially performed only in academic centers and used on a compassionate basis. This limitation led the results to be scarce, prohibiting the establishment of an evidence base that typically accompanies registration and approval of cancer therapies. This drawback was recently addressed by studies done on midgut NETs following the recent release of NETTER-1 results. In NETTER-1, ${ }^{177} \mathrm{Lu}$-DOTATATE (4 administrations of $7.4 \mathrm{GBq}$ every 8 weeks) with an augmented dose of $30 \mathrm{mg}$ octreotide long-acting release (LAR) formulation every 4 weeks was compared to $60 \mathrm{mg}$ octreotide LAR only in patients with progressive SSTR expressing midgut NETs (ileal in 75\% of patients) (Strosberg et al. 2017). The interim analysis was encouraging for ${ }^{177} \mathrm{Lu}$-DOTATATE, with an objective response of 18 vs 3\% compared to octreotide alone, with median progression-free survival (PFS) not yet reached in ${ }^{177} \mathrm{Lu}$-DOTATATE group vs 8.4 months using an augmented-dose of octreotide LAR. There was a reduced mortality in the PRRT arm (14 vs 26 deaths in control arm) which represented a 60\% lower estimated risk of death in PRRT arm than in control arm and hazard ratio for death with PRRT vs control arm being $0.4(P=0.004)$. Importantly, for an essentially palliative therapy, the toxicity profile of PRRT was acceptable and quality of life of patients was increased (Strosberg et al. 2018). In a retrospective study, survival and response rates of addition of cold SSA to PRRT as a combination and/or maintenance therapy were evaluated and compared with PRRT alone in 168 patients of advanced gastroenteropancreatic NETs. The patients were divided into two groups: group 1 received PRRT alone (81 patients) and group 2 (87 patients) received PRRT combined with SSA followed by SSA as maintenance therapy or PRRT followed by SSA as maintenance therapy. The median PFS and OS was found to be significantly higher in group 2 (48 and 91 months, respectively) compared with group 1 (27 and 47 months, respectively). This showed the potential role of SSA as a combination and/or maintenance therapy in tumor control of gastroenteropancreatic NETs who underwent PRRT (Yordanova et al. 2018). These data have provided a valuable impetus for studying the wider application of the ${ }^{68} \mathrm{Ga} /{ }^{177} \mathrm{Lu}$-DOTATATE strategy in the management of NETs and various SSTR-expressing tumors.

\section{Prognostic markers for PRRT in NET}

The main predictors of poor OS outcome after PRRT are non-specific and include high Ki-67 index (greater than $10 \%$ ), high uptake on ${ }^{18} \mathrm{~F}-\mathrm{FDG}$, involvement of more than two organ systems, local vs distant metastases, low Karnofsky performance score $(\leq 70 \%)$, high tumor burden, identified progressive disease after first PRRT, and when PRRT is delivered as salvage therapy after chemotherapy (Delpassand et al. 2014, Ezziddin et al. 2014, Bodei et al. 2015b, Kesavan \& Turner 2016, Gabriel et al. 2019, Wolf et al. 2019). In another study, highly elevated maximum standardized uptake values $\left(\mathrm{SUV}_{\max }\right)$ on pre-therapeutic ${ }^{68} \mathrm{Ga}$-DOTATOC were associated with tumor shrinkage, reduction of tumor markers, and improved overall clinical https://erc.bioscientifica.com (c) 2019 Society for Endocrinology Published by Bioscientifica Ltd. Printed in Great Britain 
condition after PRRT with 90Y-DOTATOC (Oksuz et al. 2014). Elevated baseline inflammation-based index (IBI) score (derived from serum C-reactive protein and albumin levels) and persistently elevated IBI between PRRT cycles were also associated with inferior PFS and OS in one small retrospective study in metastatic NETs (Black et al. 2019).

\section{Toxicity profiles of PRRT}

Toxicity is limited, especially when using ${ }^{177} \mathrm{Lu}$ due to its lower tissue penetration range compared with ${ }^{90} \mathrm{Y}$ (Table 2).

There is an extensive experience on safety of PRRT in NET patients and generally it is found to be well tolerated. Usually nausea and vomiting are the commonly seen acute side effects which could primarily be attributed to amino acid infusions concurrently administered with ${ }^{177} \mathrm{Lu}$-DOTATATE (Strosberg et al. 2017). Fatigue and abdominal pain can also be accompanied; however, they are usually mild and self-limiting (Strosberg et al. 2017). Hematotoxicity and nephrotoxicity have been commonly identified adverse events in patients undergoing PRRT. There have been large patient series that reported grade $3 / 4$ nephrotoxicity ranging from $0 \%(0 / 343)$ with ${ }^{177} \mathrm{Lu}$ (Bergsma et al. 2016b); 0.3\% (20/581) with ${ }^{177} \mathrm{Lu}$ (Brabander et al. 2017); $1.3 \%$ (1/74) with ${ }^{177} \mathrm{Lu}$ (Sabet et al. 2014); and to $1.5 \%(12 / 807)$ with ${ }^{90} \mathrm{Y},{ }^{177} \mathrm{Lu}$, or ${ }^{90} \mathrm{Y}+{ }^{177} \mathrm{Lu}$ (Bodei et al. 2015a). Further in six patients with a single functional kidney, no acute renal toxicity was reported; however, two patients showed reduction of glomerular filtration rate (5.3 and $13.8 \%$, respectively) with $3-5$ cycles of ${ }^{177} \mathrm{Lu}$ demonstrating that it is feasible to treat NET patients having single functioning kidney with ${ }^{177} \mathrm{Lu}$ (Ranade \& Basu 2016). Moreover, Bergsma et al. also observed that none of the risk factors (hypertension, diabetes, high cumulative injected activity, radiation dose to the kidneys and CTCAE grade) at baseline had a significant effect on renal function over time (Bergsma et al. 2016b), whereas another study recommended clinical screening of patients undergoing PRRT in regard to pre-existing risk factors such as hypertension and diabetes and suggested patients to undergo a thorough dosimetric study and should not receive a biologically effective dose higher than 28Gy (Bodei et al. 2008). The grade 3/4 hematotoxicty reported in large patient series ranged from 9.5\% (77/807) with ${ }^{90} \mathrm{Y},{ }^{177} \mathrm{Lu}$, or ${ }^{90} \mathrm{Y}+{ }^{177} \mathrm{Lu}$ (Bodei et al. $\left.2015 a\right) ; 10 \%(61 / 582)$ with ${ }^{177} \mathrm{Lu}$ (Brabander et al. 2017); 11\% (34/320) with ${ }^{177} \mathrm{Lu}$ (Bergsma et al. 2016a); and to $11.3 \%$ (23/208) with ${ }^{177} \mathrm{Lu}$ (Sabet et al. 2013a). In a meta-analysis comprising 16 studies, short-term myelotoxicity was observed in 10\% (221/2104) with PRRT monotherapy. At the same time the grade $3 / 4$ hematotoxicity was observed in $10.2 \%(7 / 68)$ of NET patients treated with ${ }^{177} \mathrm{Lu}$ (Sabet et al. 2013b) having bone metastases and no hematotoxicity apart from grade 1 anemia in one out of six NET patients treated with ${ }^{177} \mathrm{Lu}$ (Basu et al. 2016) having extensive bone marrow involvement shows that PRRT is well tolerated in this group of patients. Furthermore, MDS or AL were reported to range from $1.4 \%(3 / 208)$ with ${ }^{177} \mathrm{Lu}$ (Sabet et al. $\left.2013 a\right)$; $2.0 \%(22 / 148)$ with ${ }^{90} \mathrm{Y}$ or ${ }^{177} \mathrm{Lu}$ (Baum et al. 2018$) ; 2.2 \%$ (13/582) with ${ }^{177} \mathrm{Lu}$ (Brabander et al. 2017); and to $1.4 \%$ $(32 / 2225)$ in the meta-analysis comprising 16 studies (Kesavan \& Turner 2016). The identified risk factors for hematotoxicity were impaired renal function, low white blood cell count, extensive tumor mass, high tumor uptake on the scans and/or advanced age, cumulative administered activity (>29.6 GBq) and initial cytopenias, prior number of therapies, prior chemotherapy (alkylating agents), and prior radiotherapy (Sabet et al. 2013a, Bergsma et al. 2016b, Kesavan \& Turner 2016). At the same time, a clear correlation between dose and occurrence of therapy-related myeloid neoplasms could not be established in a cohort of 34 dosimetry assessed patients (Bodei et al. 2015a). Neither the administered radioactive dose nor the type of radionuclide was found to have a significant impact on occurrence of marrow neoplasms suggesting that intrinsic, genetically determined factors may potentially play a critical role in the pathobiology of therapy-related myeloid neoplasms (Bodei et al. 2015a, 2016). Recently, grade $3 / 4$ hepatotoxicity in NET patients with liver metastases was observed in 3\% (20/581) with ${ }^{177} \mathrm{Lu}$ (Brabander et al. 2017) and any hepatotoxicity in

Table 2 Beta-emitting radionuclides for targeted radionuclide therapy.

\begin{tabular}{|c|c|c|c|c|}
\hline Radionuclide & Half-life (days) & Max energy of emitted particle (Mev) & Path length (mm) Max-Mean & Useful $\gamma$ for post-therapy imaging \\
\hline 177Lu & 6.7 & 0.5 & $2.2-0.3$ & Yes \\
\hline $90 Y$ & 2.7 & 2.3 & $11.9-2.5$ & No \\
\hline 131| & 8 & 0.81 & $2.4-0.3$ & Yes \\
\hline
\end{tabular}

d, days; ${ }^{131}$ I, Iodine-131; ${ }^{177} \mathrm{Lu}$, Lutetium-177; Mev, mega electron volt; mm, millimeter; ${ }^{90 Y}$, Yttrium-90.

https://erc bioscientifica.com

https://doi.org/10.1530/ERC-19-0165
(C) 2019 Society for Endocrinology Published by Bioscientifica Ltd. Printed in Great Britain 


\section{Endocrine-Related} Cancer
$10.8 \%(10 / 93)$ with either of ${ }^{90} \mathrm{Y}$ or ${ }^{177} \mathrm{Lu}$ or ${ }^{90} \mathrm{Y}+{ }^{177} \mathrm{Lu}$ based PRRT (Riff et al. 2015). Also, cardiotoxicity was reported for the first time in a patient with cardiac metastases having normal heart function before therapy; however, he developed new-onset cardiomyopathy following two cycles of ${ }^{177} \mathrm{Lu}$ with persistent cardiac dysfunction for 3 years after PRRT (Hendifar et al. 2018). Also, repeated PRRT with eight or more cycles having median administered activity of $63.8 \mathrm{GBq}$ (range 52-96.6) was found to be safe and well tolerated without any life-threatening adverse events (grade 4) (Yordanova et al. 2017). It was also observed that the frequency of nephrotoxicity and hematotoxicity was highest with ${ }^{90} \mathrm{Y}$ followed by ${ }^{90} \mathrm{Y}+{ }^{177} \mathrm{Lu}$ and least with ${ }^{177} \mathrm{Lu}$ based PRRT (Bodei et al. 2015a). Further, in a prospective trial of 65 gastroenteropancreatic-NET patients treated with four cycles of $7.8 \mathrm{Gbq}{ }^{177} \mathrm{Lu}$-octreotate in combination with $1650 \mathrm{mg} / \mathrm{m}^{2}$ capecitabine $(n=28)$ and $1500 \mathrm{mg} / \mathrm{m}^{2}$ temozolomide $(n=37)$, the addition of radiosensitizing chemotherapy did not significantly increase the modest reversible hematotoxicity of PRRT (Kesavan et al. 2014).

Several unidentified individual susceptibilities to radiation-associated disease have also been reported (Bodei et al. 2015a). PRRT may be associated with renal or hematological (bone marrow) toxicities that can be minimized by adequate precautions and proper and safe dosing (Bodei et al. 2014a,b, Brabander et al. 2017, Bergsma et al. 2018).

Although not randomized, the Erasmus group experience also reported a good tumor response rate in patients with SSTR expressing metastatic bronchial and pancreatic NETs with limited severe long-term toxicities, leukemia or MDS being observed in $2 \%$ of patients (Brabander et al. 2017).

\section{PRRT in PPGL}

The use of PRRT for patients with PPGLs who had high tumor SSTR expression has mainly been reported in retrospective small case series or case reports (only three single-center prospective studies) (Table 2). Overall, after PRRT, 89.8\% (95\% CI: 84.1-95.0\%) of pooled patients had achieved disease stabilization/partial response of inoperable/metastatic PPGL with symptomatic improvement in the vast majority of patients (Figs 4 and 5). No statistically significant heterogeneity among included studies was found $\left(I^{2}=37.6 \%, P=0.099\right)$. Importantly, disease status at the time of therapy is not always well described in the studies (Table 3).

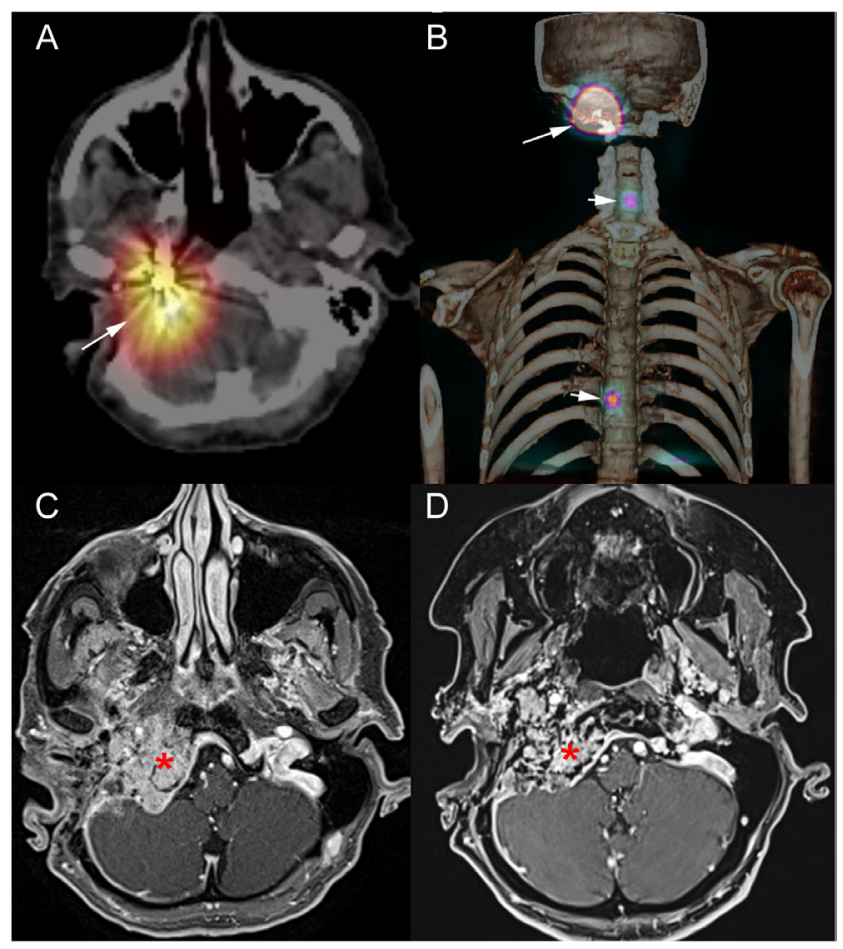

Figure 4

177Lu-DOTATATE in a SDHB patient with metastatic jugular paraganglioma (PGL). (A, B) Post-therapy SPECT/CT following the first administration of 177Lu-DOTATATE. (A) SPECT/CT fusion images centered over the jugular PGL (long arrow). (B) Volume rendering (jugular PGL: long arrow, metastases: short arrows). (C) Pre-therapeutic MRI. (D) Post-therapeutic MRI (2 months following the fourth cycle of 177Lu-DOTATATE) showing a tumor shrinkage (asterisk).

Treatment response to PRRT has been evaluated in several ways in the included studies as reported in Table 3 (i.e. by using morphological and/or functional and/or clinical data). Nevertheless, we did not find a significant heterogeneity $\left(I^{2}<50 \%\right)$ in the performed meta-analysis about the proportion of response or stable disease after PRRT. Therefore, it is unlikely that the different methods used for evaluating treatment response can influence the pooled results. Even if sometimes combined treatment was performed (as reported in an added column in Table 3 ), it is unlikely that this has influenced the pooled results on PRRT due to the mild statistical heterogeneity that we have detected among studies.

Van Essen et al. treated 12 patients with metastatic PGLs (five with head and neck lesions) with ${ }^{177} \mathrm{Lu}$-DOTATATE. Six patients showed stable disease, two patients showed response, three patients showed progressive disease and data was unavailable for one patient. However, separate results between tumor locations were not provided (van Essen et al. 2006). Forrer et al. reported the response rates of PRRT using either ${ }^{90}$ Y-DOTATOC (25 patients) or 


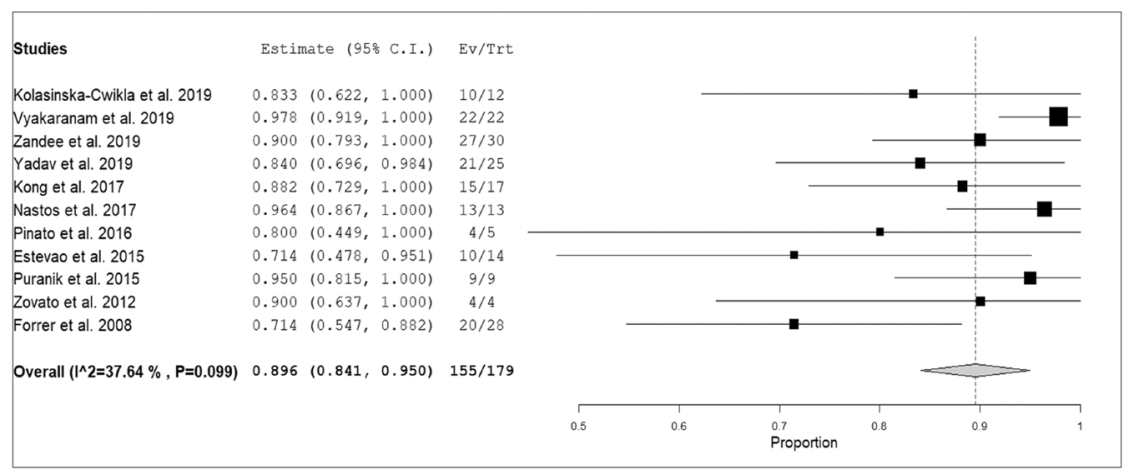

\section{Figure 5}

Proportion of PPGL patients with partial response or stable disease after PRRT. Plots of individual studies and pooled proportion (with 95\% confidence interval) of inoperable/metastatic PPGL patients with response or stable disease after PRRT (random-effects model). The size of the squares indicates the weight of each study. Mild heterogeneity among studies was evident ( 12 test $=37.6 \%, P=0.099)$.
${ }^{177} \mathrm{Lu}-\mathrm{DOTATOC}$ (3 patients) in surgically unresectable PPGLs (Forrer et al. 2008). The authors reported disease stabilization in approximately $50 \%$ of the cohort, a response rate which was considered as inferior compared to their own experience in gastroenteropancreatic NETs.

Treatment response may include locoregional control of the primary tumor and complete disappearance of metastases (Gupta et al. 2014). Zovato et al. had treated four inoperable hereditary HNPGLs with ${ }^{177} \mathrm{Lu}$-DOTATATE (three to five courses) and all had stable disease or partial response documented on SSTR imaging (Zovato et al. 2012).

Puranik et al. in Bad Barka included nine patients with inoperable HNPGLs including two patients previously treated by radiotherapy 13 months earlier (Puranik et al. 2015). All tumors had marked avidity for ${ }^{68} \mathrm{Ga}$-DOTATOC on PET imaging. Eight patients had jugular PGL with tumor multifocality in four patients with coexistence of thoracic PGL in two patients and thoraco-abdominal PGLs in one patient. One patient with a large vagal PGL (and multifocality) had painful bone metastases. The radiopharmaceutical used was either ${ }^{90}$ Y-DOTATATE (five patients) or combination of ${ }^{90}$ Y-DOTATATE and ${ }^{177} \mathrm{Lu}$-DOTATATE (four patients). The number of treatment courses ranged from 2 to 4 . Based on ${ }^{68} \mathrm{Ga}$-DOTATOC PET/CT, four patients showed partial metabolic response (PR, 15-25\% decrease in $\mathrm{SUV}_{\text {max }}$ ) and the remaining five patients showed stable disease SUV $_{\max }$ in target lesions - 15-25\%). Patients with partial metabolic response had small reductions in tumor size, but insufficient to achieve morphological partial response criteria. No new lesions were found in any patient, but they did not describe the clinical course of the disease, and it is probable that these tumors had slow or minimal progression prior to entering the study. Symptomatic improvement was observed in all six patients and no patients had worsening quality of life. No renal or hematologic toxicity was observed in this series.
Estêvão et al. also reported that $90 \%$ of patients with jugulotympanic PGLs had symptomatic improvement or stabilization after PRRT (Estevao et al. 2015).

Pinato et al. also reported disease stabilization in $3 / 5$, partial response in $1 / 5$, and progressive disease in $1 / 5$ metastatic PGL (five with bone metastases and one with lung metastases), with all being previously documented as progressive disease (Pinato et al. 2016).

Kong et al. had treated 20 metastatic PPGLs (7 SDHB, 1 SDHD, 2 without SDHx, 10 unknown status) with ${ }^{177} \mathrm{Lu}-\mathrm{DOTATATE}$ in two centers (Kong et al. 2017). Thirteen patients had sympathetic PPGL, 5 had HNPGL and 2 had both sympathetic PPGL and HNPGL. In 9 patients treated at Peter MacCallum Cancer Centre, the second through fourth cycles were given with radiosensitizing chemotherapy (fluorouracil in three patients, oral capecitabine in one patient, capecitabine/ temozolomide in one patient and, temozolomide alone in four patients) unless contraindicated. Response was assessed on ${ }^{68} \mathrm{Ga}$-DOTATATE PET/CT imaging using a Krenning-like semi-quantitative scale as follows: stable response $=$ unchanged intensity of previous abnormal uptake, partial response=reduction in intensity by 1 Krenning point in at least one tumor site, complete response (total disappearance of abnormal uptake of previously avid lesions), progressive disease (an increase in intensity or extent of previous abnormal uptake or development of new avid lesions). Minor response was also used to describe smaller size changes not meeting partial response criteria on RECIST 1.1 (10\% to 30\% decrease in maximum diameter of target lesions). Fourteen of 20 patients were treated for uncontrolled secondary hypertension. Among 13/14 with follow-up clinical information, eight required reduced doses of anti-hypertensive medications. Eight of 13 patients had symptomatic improvement and $2 / 13$ had complete resolution of symptoms at 3 months after PRRT. In 7/20 patients with plasma metanephrine/normetanephrine data, (c) 2019 Society for Endocrinology Published by Bioscientifica Ltd. Printed in Great Britain 


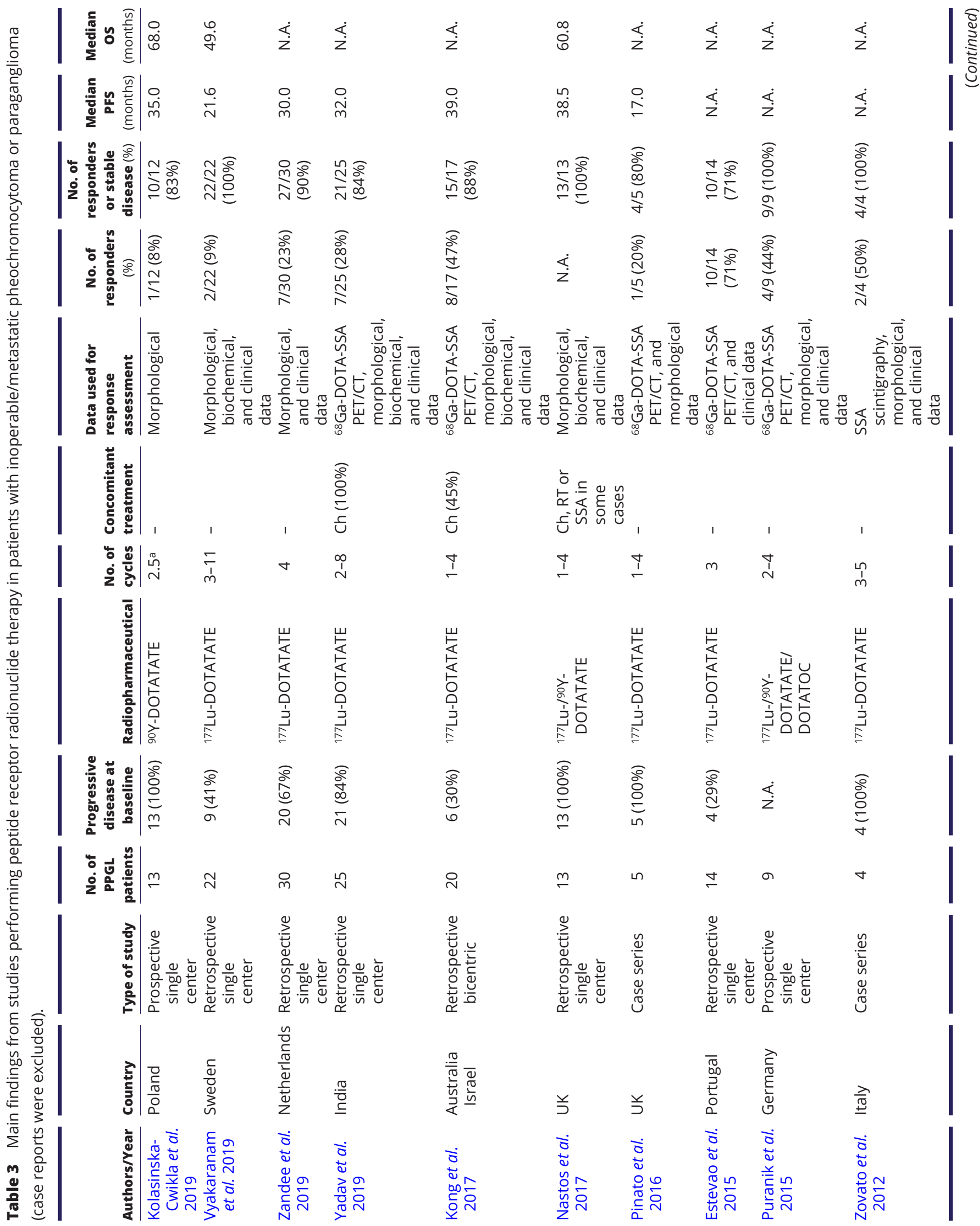




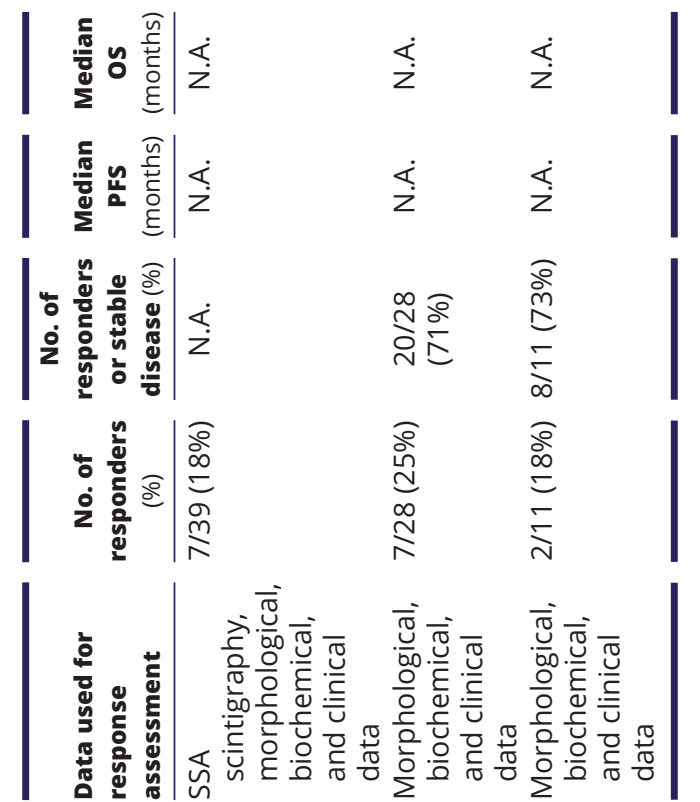

plasma metanephrine and/or normetanephrine decreased in 6/7 patients, whereas plasma chromogranin $\mathrm{A}(\mathrm{CgA})$ decreased in 12/14 patients with available plasma CgA data. Among the $17 / 20$ patients evaluable for SSTR response, $8(47 \%)$ had a partial response, $7(41 \%)$ had stable disease, and 2 (12\%) had disease progression. Of the $14 / 20$ patients with available and evaluable disease by RECIST 1.1, 4 (29\%) had partial RECIST response, 1 (7\%) had minor morphologic regression, 7 (50\%) had stable disease, and 2 (14\%) had progression. Median PFS was 39 months; median OS was not reached (five deaths; median follow-up, 28 months). Four and two patients had grade 3 lymphopenia and thrombocytopenia, respectively. Renal impairment in two patients were attributed to underlying impaired renal function (one secondary to systemic amyloidosis, one not described). Hypertension flare was observed in one patient, $3 \mathrm{~h}$ after PRRT administration. No additional toxicity was apparent with its concomitant use of radiosensitizing chemotherapy. Further, four patients who progressed or deteriorated with tumor progression or had recurrence of hypertension following first cycle of PRRT were re-treated with additional cycles of PRRT ranging from 1 to 8 cycles. Two patients were provided additional maintenance therapies for persisting disease with further favorable response.

Nastos et al. had described the outcomes of 22 patients with progressive/metastatic PPGLs treated with either ${ }^{131}$ I-MIBG (11 patients), ${ }^{90}$ Y-DOTATATE (8 patients), ${ }^{177} \mathrm{Lu}$-DOTATATE (1 patient) or combination of ${ }^{131}$ I-MIBG with ${ }^{90} \mathrm{Y} /{ }^{177} \mathrm{Lu}$-DOTATATE (2 patients) (Nastos et al. 2017). They have shown a response in 11 of 11 (100\%) treatments with ${ }^{90}$ Y-DOTATATE alone or in combination and a mean PFS of 43 months. In the subgroup of 15 patients with extradrenal PGLs (21 treatments, from which 13 were with PRRT and 8 with ${ }^{131}$ I-MIBG), PRRT performed significantly better than ${ }^{131} \mathrm{I}-\mathrm{MIBG}$ in terms of OS, PFS, and response to treatment. Four patients (18.1\%) developed renal toxicity related to radionuclide treatment, with grade 3 renal toxicity in a patient treated with ${ }^{90}$ Y-DOTATATE and ${ }^{131}$ I-MIBG. Although this study mainly relies on the use of ${ }^{90}$ Y-DOTATATE for PRRT, it illustrates that SSTR-directed targeted radionuclide therapy should therefore be favored over ${ }^{131} \mathrm{I}-\mathrm{MIBG}$ in this subgroup of patients.

In a retrospective study by Zandee $e t$ al., 30 inoperable or metastatic PPGL patients underwent PRRT with upto four cycles of ${ }^{177} \mathrm{Lu}$-DOTATATE $(7.4 \mathrm{GBq} / \mathrm{cycle}$ ) (Zandee et al. 2019). Twenty of 30 patients treated were progressive at start. According to RECIST 1.1, 7 (23.3\%) patients had partial response and 20 (66.7\%) patients had stable disease, whereas 3 (10\%) patients had progressive disease. 
In 20 patients with baseline disease progression, tumor control was observed in 17 (85\%). Median PFS was 30 months and median OS was not reached (nine deaths; median follow-up, 52.5 months). Grade $3 / 4$ subacute hematotoxicity occurred in $6(20 \%)$ patients. One patient developed MDS after 45 months following six cycles of ${ }^{177} \mathrm{Lu}$-DOTATATE (including retreatment, cumulative dose 44.4 GBq) and died after 4.5 years of first cycle of PRRT due to complications. This patient was not treated with any prior chemotherapy or ${ }^{131}$ I-MIBG therapy and lacked bone marrow metastases. A reversible subacute adverse event due to cardiac failure following possible catecholamine release/crisis occurred in two patients (6.7\%).

In a recently published retrospective study by Vyakaranam et al., 22 patients received ${ }^{177} \mathrm{Lu}$-DOTATATE ( $n=3$ with four cycles of $7.4 \mathrm{GBq}$ and $n=19$ with dosimetry-guided PRRT where as many cycles (3-11) were administered until $23 \mathrm{~Gy}$ to the kidneys or $2 \mathrm{~Gy}$ to bone marrow was reached) achieving a median OS of 49.6 (range 8.2-139) months and a median PFS of 21.6 (range 6.7-138) months (Vyakaranam et al. 2019). Nine of 22 patients treated were progressive at start. According to RECIST 1.1, two (9.1\%) patients had partial response, 20 (90.9\%) patients had stable disease. Among the nine progressive patients at the start of PRRT, one achieved partial response and eight stable diseases with a median decrease of $14 \%$ (range 0-56\%) in tumor size. The biochemical response was evaluated with a reduction in catecholamines in 11 of 12 evaluable patients (91.6\%) with $>50 \%$ reduction in $3 / 12$ (25\%) of patients, whereas increase in catecholamines was observed in 1/12 (8.3\%) patients. Further, a reduction in CgA was observed in 13 of 15 evaluable patients (86.7\%) with $>50 \%$ reduction in $6 / 15(40 \%)$ of patients, whereas increase in CgA was observed in 2 (13\%) patients. Thus, biochemistry indicated progressive disease in two patients with stable disease on CT/MRI but, in the remaining patients, the biochemical and morphological responses were in agreement. Ten of 22 patients had catecholaminerelated symptoms, which in two were aggravated during PRRT, including the development of hypertensive crisis. No renal toxicity and only grade $1(n=10)$ or grade 2 $(n=6)$ hematological toxicity was reported in 16/22 (73\%) patients. High Ki-67 (>15\%) and prior PRRT therapy because of progression constituted negative predictive factors for OS, whereas only high Ki-67 (>15\%) constituted negative predictive factor for PFS.

In a recently published prospective study by Kolasinska-Cwikla et al., 13 inoperable or metastatic $S D H x$ related PPGL patients ( $S D H B, n=5 ; S D H D, n=8$ ) underwent a 2.5 mean cycles of ${ }^{90} \mathrm{Y}$-DOTATATE (mean $3.4 \mathrm{GBq} /$ cycle)
(Kolasinska-Cwikla et al. 2019). All 13 patients treated were progressive at start. According to RECIST 1.0, after 1 year of PRRT therapy, nine (82\%) of 11 patients had stable disease, whereas $2 / 11$ (18\%) patients had progressive disease and none of the patients demonstrated partial response. Grade 3 renal toxicity occurred in two patients who also demonstrated grade 3 anemia. Median PFS and OS were 35 and 68 months, respectively; however, they were 12 and 25 months, respectively for SDHB patients and did not reach for SDHD patients. The OS was 25 months and PFS was 10 and 12 months for patients with liver and bone metastases, respectively. In long-term follow up (duration unspecified), all $S D H B$ patients and 3 SDHD patients progressed with 4 (80\%) deaths in $S D H B$ and $2(25 \%)$ deaths in SDHD patients.

In a retrospective study by Yadav et al., 25 patients received a median of 3 (range: 2-8) cycles of PRRT with ${ }^{177} \mathrm{Lu}$-DOTATATE and concomitant capecitabine $\left(1250 \mathrm{mg} / \mathrm{m}^{2}\right.$ for 15 consecutive days commencing on the morning of ${ }^{177} \mathrm{Lu}$-DOTATATE therapy) (Yadav et al. 2019). According to RECIST 1.1, 7 (28\%) patients had partial response, 14 (56\%) patients had stable disease, and the remaining $4(16 \%)$ patients had progressive disease. The biochemical response was evaluated with a reduction in CgA observed in 23 (92\%) of patients with $>50 \%$ reduction in $7(28 \%)$ of patients, whereas increase in CgA was seen in $2(8 \%)$ patients. The symptomatic response was evaluated by change in anti-hypertensive drugs. Fourteen of 25 patients were on anti-hypertensive drugs and its reduction was observed in $6(43 \%)$ patients, whereas no change occurred in 8 (58\%) patients. The median PFS was 32 months and the median OS was not reached (seven deaths); however, the median OS in progressive group was 16 months (95\% CI, 14-24 months). All the patients reported improved general well-being without any severe hematotoxicity or nephrotoxicity. They concluded that concomitant therapy did not demonstrate superiority in comparison to reported outcomes of published PRRT monotherapy. Furthermore, a case report describing metastatic mediastinal PGL improved by combination of ${ }^{177} \mathrm{Lu}$-DOTATATE and capecitabine has also been reported (Ashwathanarayana et al. 2017).

In conclusion, overall results suggest favorable objective disease control, reflected mainly by partial response or stable disease (Fig. 5). The rate of objective response on conventional imaging seems to be lower than that for gastroenteropancreatic NETs. One could speculate about possible lower radiosensitivity of PPGL, but this question cannot be answered currently and would require specific prospective evaluation. Patients should (c) 2019 Society for Endocrinology Published by Bioscientifica Ltd. Printed in Great Britain 
undergo both ${ }^{123} \mathrm{I}-\mathrm{MIBG}$ and ${ }^{68} \mathrm{Ga}-\mathrm{DOTA}-\mathrm{SSA}$ imaging, and based on the results, the first-line therapy should be chosen (Vyakaranam et al. 2019). In case of mosaic expression of the two tracers, treatment with both can be considered, and if any lesion/s lack uptake of both the tracers, then it can be targeted by additional beam radiation (Vyakaranam et al. 2019). Furthermore, PRRT with combined and/or maintenance cold SSA therapy should be considered as it demonstrated superior results compared to PRRT monotherapy in NETs (Yordanova et al. 2018). However, currently there are no data supporting this in the setting of PPGL. These data have provided a valuable impetus for studying the wider application of the ${ }^{68} \mathrm{Ga} /{ }^{177} \mathrm{Lu}$-DOTATATE strategy in the management of NETs and various SSTR-expressing tumors.

Given the favorable efficacy, further prospective PRRT trials, including use of radiosensitizing chemotherapy, are warranted. There is currently an ongoing phase II study at the NIH (NCT03206060) that evaluates ${ }^{177} \mathrm{Lu}$-DOTATATE for metastatic/inoperable SDHx and apparently sporadic PPGLs. Interestingly, inclusion requires progressive disease by RECIST 1.1 with or without symptoms within the last 12 months. The primary objective relies on 6-month PFS. Further, future prospective trials comparing PRRT and HSA ${ }^{131}$ I-MIBG therapy determining their efficacy and radiation safety profile should be studied.

\section{Potential indications of radiotherapeutic in the management of PPGL}

\section{Head and neck PGL}

Most HNPGLs exhibit an indolent behavior and almost always do not secrete catecholamines and hence need not always show symptoms of catecholamines excess. The application of targeted internal radiotherapy should therefore be discussed in limited situations in non-metastatic patients. In a large HNPGL, surgical management is often challenging due to complex anatomy and proximity to critical structures. This is particularly true for jugular PGLs arising from the adventitia of the dome of the jugular bulb (glomus jugulare PGLs) that may extend into the pars nervosa of the jugular foramen, jugular vein, sigmoid sinus, carotid artery, middle ear, mastoid space, and posterior cerebellar fossa. In few patients, subtotal surgical resection can be considered for limiting cranial nerve morbidity. Surgery of vagal nerve PGL is also questionable since it always requires the sacrifice of the vagus nerve. In recent years, various forms of radiotherapy have been reported in these tumors, with favorable outcomes. Vagal nerve PGL is usually related to SDHx mutation (mainly SDHD) in approximately $40 \%$ of patients. The impact of detecting multiple HNPGLs, even millimetric in size, is of a major clinical importance. It is important to recall that bilateral neurologic injuries affect respiration, deglutition and phonation and are associated with chronic complications and vital risks (Suarez et al. 2013). In these patients with tumor multifocality, any post-operative complications may compromise subsequent interventions. The initial staging of an HNPGL is currently based on the use of anatomical and functional imaging approaches to determine the tumor extension into the bone and surrounding soft tissue, to determine tumor multiplicity not only in the head and neck area but also elsewhere in the body, and finally, to exclude any metastases. Although the locoregional extension of HNPGLs is well determined and delineated by anatomic imaging (temporal bone CT, MR angiography), PET imaging using specific tracers performs better for detecting multiple lesions and can increase diagnosis confidence for tumor extensions classified as doubtful on anatomic imaging. Furthermore, previous treatments can lead to artifacts that can seriously degrade the quality of anatomic imaging.

An individual management approach is absolutely necessary in HNPGL patients, especially those with multifocality with vagus nerve involvement. In all patients, a wait-and-scan policy could be the primary option for defining the growth pattern. Patients undergoing such an approach should be informed that many tumors continue to grow, and may eventually require treatment. In head and neck due to the presence of important structures and nerves, at times even a minor growth may lead to symptoms and complications. External beam radiotherapy (EBRT) should be considered as an option in patients with inoperable HNPGL (i.e. unresectability of the primary tumor or tumor relapse due to invasion into surrounding tissue) having progressive and/or symptomatic disease. It has been reported that higher doses are associated with improved local control (Vogel et al. 2014, Breen et al. 2018). The advantage of PRRT over radiotherapy is potentially to treat multiple tumors during the same session without any risk of nerve palsy. In patient with a single inoperable HNPGL, the indication of systemic PRRT vs locoregional treatment with EBRT needs to be discussed on an individual basis, depending on potential benefits and estimated risks of both strategies. EBRT can be provided first and PRRT could be given in cases who progress on EBRT. PRRT possibly could act synergistically 
after debulking surgery of large PGL since it may have more limited effect on very large tumors. In cases of large PGL, PRRT with ${ }^{90} \mathrm{Y}$ only or alternating it with ${ }^{177} \mathrm{Lu}$ to prevent higher renal toxicity can be considered.

\section{Retroperitoneal PPGL}

The majority of these patients are clinically symptomatic due to catecholamines excess which may get controlled by surgery, regardless of the surgical approach (open or endoscopic). Although minimally invasive surgery can also be performed in most retroperitoneal PGLs, surgery can be more challenging due to possible adhesions to major retroperitoneal vessels leading to surgical conversions. Therefore, surgical strategy should be tailored to each situation with the knowledge of the genetic status since upto $70 \%$ of patients with extra-adrenal retroperitoneal PGL may carry germline mutations in SDHx or VHL genes (Gimenez-Roqueplo et al. 2003, Neumann et al. 2004, Amar et al. 2005, 2007, Brouwers et al. 2006). Large PPGLs and those associated to $S D H B$ mutation are associated with a higher risk for metastatic spread and imaging is required to fully localize the extent of disease at whole-body scale. Surgery should always be considered as first-line therapy. In patients with non- or incompletely resectable large PGL, a radiotherapeutic management could be considered (also as complementary therapy after debulking surgery), especially for patients with $S D H B$ mutation which are prone to develop metastases and symptomatic patients (e.g. pain, uncontrolled hypertension). The choice of the therapeutic radiopharmaceutical can be tailored to diagnostic scans using their uptake pattern on companion diagnostics. The use of PRRT using ${ }^{177} \mathrm{Lu}-\mathrm{DOTA}-S S A$ will be better suited to SDHx-related PPGL than ${ }^{131}$ I-MIBG.

\section{Metastatic PPGL}

The management of patients with metastatic PPGL can be challenging and may rely on surgery, interventional radiology, chemotherapy, external beam radiation, or other therapeutic options (Nolting et al. 2019). Primary tumor resection can be recommended based on careful evaluation of tumor burden as well as the extent of metastatic disease. Exercising this option helps to reduce cardiovascular and other such risks from high catecholamine levels and alleviate/prevent symptoms from the tumor's invasion of surrounding structures. Treatment of metastases with a curative intent to treat may also be considered in individual patients with oligometastatic disease which remains a rare situation.
In rapidly progressive metastatic PPGL, patients can be treated with various chemotherapeutic agents. Although there exist various options as well as biases in the literature, currently CVD is still considered as the first-line therapeutic modality, especially for rapidly progressive disease (Niemeijer et al. 2014). In SDHB patients, temozolomide may be considered for tumor stabilization as a maintenance regime subsequent to CVD chemotherapy (Hadoux et al. 2014). Sunitinib is currently under evaluation (NCT01371201). Palliative surgery followed by external radiotherapy can be indicated in metastatic PPGL with a high risk for neurologic compression (e.g. spinal cord compression). In metastatic PPGL with slow pace of growth and limited tumor volume, ${ }^{131}$ I-MIBG or PRRT using ${ }^{177} \mathrm{Lu}$-DOTA-SSA can be indicated in patients with positive scans for the respective radiopharamaceuticals. Additionally, combined ${ }^{177} \mathrm{Lu}$-DOTA-SSA and cold SSA can be considered in SSTR positive patients and its efficacy can be determined in future trials. However, currently there are no data supporting this in the setting of PPGL. Moreover, patients with tumor phenotype showing both or discordant molecular targets on various lesions may theoretically benefit from a combined or sequential radionuclide therapeutic approach using PRRT and 131I-MIBG, but further trials are required to assess efficacy and potential toxicity of this regimen.

\section{Healthcare environment}

Management of PPGL is complex and it is therefore strongly encouraged to refer these patients to experienced centers with high-volume surgical procedures. Core members of the team should include various specialities (oncologists, radiation oncologists, endocrinologists, otorhinolaryngologist/endocrine surgeons, radiologists/ nuclear physicians, pediatricians, clinical geneticists, and pathologists) who work in the same center and have meetings on the regular basis. Imaging scans can be performed elsewhere if available and then can be interpreted by this core team.

\section{Research avenues}

\section{Dosimetry-based regimens}

Dosing of targeted radionuclides is often based on empirical observations and is not subject to the precise, patient-specific treatment planning that is standard for external beam radiotherapy. Based on published studies, (c) 2019 Society for Endocrinology Published by Bioscientifica Ltd. Printed in Great Britain 
it is possible that better outcomes could be achieved with increased cumulative dose delivery to tumors. The main challenge for systemic radiation therapy remains to optimize the dose delivery to a tumor, while minimizing normal tissue irradiation. In therapeutic nuclear medicine, the term 'dose' is a misnomer that is often used for describing the administered activity (expressed in units of Becquerel (Bq)) of a radiopharmaceutical. The 'absorbed dose' (expressed in units of gray (Gy)) is dependent on many factors including the administered activity but most importantly on tumor characteristics (target expression, metabolic activity, volume, and perfusion). Calculation of the absorbed dose is more complex than for external radiotherapy since the cells and organs are irradiated not only for seconds or minutes, but continuously, over a long period of time with everchanging dose rate. Therefore, it relies on repeated blood/urinary collections and imaging procedures following therapy. Several modern dosimetry models have been developed in order to optimize PRRT for individual patients (Taieb et al. 2015, Del Prete et al. 2018, Huizing et al. 2018). In order to circumvent some difficulties for estimating the absorbed dose by the tumor, two main options have been proposed for achieving radiation dose intensification (Cremonesi et al. 2018). One is the standard $7.4 \mathrm{GBq}$ per cycle with variation in number of cycles until the individual limit of kidney/bone marrow biologic effective dose is reached (Sandstrom et al. 2013, Sundlov et al. 2017) or the other is a four fixed cycles with variable activity per cycle to reach the dose limits (Del Prete et al. 2017). The time interval between therapeutic cycles could also be tailored to individual situations.

Preliminary results of a trial in NETs (P-PRRT, NCT02754297) have shown that the use of patientspecific PRRT dosimetry might increase absorbed dose delivered to a tumor (median 1.26-fold; range: 0.47-2.7fold) compared to fixed-dose regimen, without increased toxicity (oral communication OP-181, Del Prete et al. 2018). A prospective evaluation of PRRT in PPGL patients with integration of a dosimetry-based approach (at voxel level analysis) would be an important step toward treating PPGL patients. Roadmaps to improvements not only include the use of synergistic effects of radiosensitizers but also knowledge regarding the relationships between tumor genotype and cellular sensitivity to ionizing radiations.

\section{Biomarkers of response to PRRT}

Therapeutic response to PRRT is often delayed and posttherapy scans or regular ${ }^{68} \mathrm{Ga}$-DOTA-SSA PET/CT scans often show disease stabilization with some clinical and biological improvement. Furthermore, bone metastases are often detectable only on molecular imaging and not measurable according to CT criteria and therefore not evaluable on RECIST. Assessment of response to PRRT would probably require a specific composite scoring with the integration of tumor uptake as a continuous variable. Beyond classical uptake parameters, it is of prime importance to find new biomarkers of response. One of the great advantages of PET relative to other imaging modalities is its inherent quantitative nature. Traditionally, PET image analysis in the field of oncologic applications has been restricted to the use of semiquantitative indices, such as SUV or SUV-derived indices. Currently, nuclear imaging is ideally placed via radiomics approaches (Kumar et al. 2012, Lambin et al. 2012, GarciaCarbonero et al. 2015, O'Connor et al. 2015). Over the last few years, a lot of interest has been concentrated on the development of PET image segmentation algorithms allowing the robust and reproducible determination of 3D tumor volumes from PET reconstructed images. As such, the use of PET image-derived 3D tumor volumes has in turn increased the potential of further exploring the information available in PET tumor images. Further analysis consists of assessing the PET tumor shape and/or heterogeneity in intratumoral activity. Intratumoral heterogeneity has been found to demonstrate superior prognostic performance in predicting both PFS and OS in 141 patients of NETs (Werner et al. 2017) and OS in 31 patients of pancreatic NETs (Werner et al. 2019). These new parameters that may reflect, depending upon the radiotracer used, various biological processes that could be used for assessment of response to PRRT (Werner et al. 2017, 2019). We can anticipate that combination of radiomics, tumor grade, and molecular biomarkers (e.g. transcriptomics, miRNA, DNA, metabolomics) will offer an optimal multiparametric approach for more individualized management to patients (Bodei et al. 2018). It is expected that machine learning technology will help to improve parameter selection and combination compared to more traditional statistical analysis, albeit the need for extensive validation and evaluation across centers and patient populations. Together with dosimetry, these biomarkers of treatment response will enable more individualized treatment plans.

\section{Alpha emitters}

Until now, experience with therapeutic applications of nuclear medicine was based on beta-emitting 
radionuclides. Beta emitters are characterized by a path length in the range of millimeters and a low linear energy transfer (LET) (Navalkissoor et al. 2019). The biological effectiveness of the deposited radiation is inversely correlated with the LET. From a radiobiological standpoint, there are significant advantages of using alpha emitters due to their shorter path length of 40-100 microns and much higher LET (Navalkissoor et al. 2019). As a result, alpha emitters deposit much more energy along their path, resulting in greater cytotoxicity than seen with beta radiation, which manifests itself through mechanisms such as apoptosis, autophagy, necrosis, and mitotic catastrophe (Baidoo et al. 2013, Wadas et al. 2014). Until recently, alpha-emitters were only used in experimental settings. PPGL as many NETs present or develop bone metastases, which may lead to adverse skeletal-related events (SRE) including pain and neurological compression (Ayala-Ramirez et al. 2013). SREs can lead to significant morbidity, impact functional status, and alter patient's quality of life. The high incidence of osteoblastic metastatic bone disease should allow for the use of bone-seeking radiopharmaceuticals in carefully selected patients who have bone scan-positive lesions. Radium-223 dichloride $\left.{ }^{223} \mathrm{Ra}\right)$ is a bone-seeking calcium mimetic alpha emitter that accumulates in areas of increased bone turnover and has been approved for the treatment of metastatic prostate cancer to the bone. Following the results of the ALSYMPCA (ALpharadin in SYMptomatic Prostate CAncer) Phase III ${ }^{223}$ Ra multinational trial (Parker et al. 2013), the FDA granted full approval in May 2013 with subsequent approval by the European Union. In contrast to other bone-seeking radiopharmaceuticals, ${ }^{223} \mathrm{Ra}$ therapy demonstrates significant survival improvements compared to the placebo. New clinical trials are underway to examine ${ }^{223} \mathrm{Ra}$ efficacy in breast cancer, lung cancer and osteosarcoma. Further studies are necessary to specifically assess the role of ${ }^{223} \mathrm{Ra}$ in palliation of extensive metastatic bone disease in endocrine malignancies such as PPGL, which present with bone lesions in more than $50 \%$ of metastatic patients (Zelinka et al. 2008). A case report has shown an improvement in pain control, mobility, and overall quality of life in a 26-year-old woman with extensive bone disease in a $S D H B$-related metastatic PGL treated with ${ }^{223} \mathrm{Ra}$ (Makis et al. 2016).

Alpha-particle emitting radiopharmaceuticals have also been evaluated in small series for intra-arterial (IA) PRRT in patients with liver metastases. IA PRRT resulted in a four-fold higher intrahepatic tumor accumulation compared to intravenous infusion due to high firstpass extraction, decreasing to 1.3 times greater at $72 \mathrm{~h}$
(Kratochwil et al. 2011). In a pilot study of patients (in 6 patients) who previously failed treatment with a beta emitter PRRT, IA therapy with ${ }^{213} \mathrm{Bi}$-DOTATOC for liver metastases produced durable responses with acceptable toxicity in NETs (Kratochwil et al. 2014). By contrast, systemic administration of alpha-particle emitting SSA would possibly be an interesting approach in PPGL but this would require to perform phase I studies in experienced medical centers.

Recently, strong anti-tumor effects of $\alpha$-emitting meta-211At-astato-benzylguanidine have been reported in a PC12-cell line mouse xenograft PHEO-bearing mouse model (Ohshima et al. 2018).

\section{Combined strategy}

In the recent years, immunotherapy has gradually gained an important role in oncology. Checkpoint inhibitors (PD-1/PD-L1) have opened up exciting new treatment pathways in metastatic cancers (Galluzzi et al. 2018). Predictors of response are multiple (e.g. high mutation burden/neoantigen burden, high PD-L1 expression, and presence of pro-immunogenic driver mutations). A recent study has shown that the expression of PD-L1 and extent of immune infiltration of small bowel NETs is heterogeneous (Cives et al. 2019). The effect of PPGL driver mutations on these parameters and response to immunotherapy would be of particular interest. Immunity can be dissected with large-scale technologies (e.g. mutational landscape, transcriptome, major histocompatibility complexassociated peptidome of tumor cells, T-cell receptor repertoire, presence of tumor-infiltrating lymphocytes and its detailed characteristics, evaluation of cytokines, and microenvironment assessment). For tumors with low tumor mutation burden such as NETs, one approach for increasing treatment efficacy would be to increase mutational/neoantigen load (Lawrence et al. 2013, Chauhan et al. 2018). A preclinical study has shown that PRRT leads to increased infiltration of antigen-presenting cells and natural killer cells into tumors, suggesting a mechanistic role for the inflammatory response followed by increased innate immunity in the action of PRRT (Wu et al. 2013). The immunotherapy with external beam radiation, including targeted internal therapy could synergistically play a significant role, which needs to be further evaluated. An emerging challenge is how to combine radiation therapy with immunotherapy effectively (Serre et al. 2016, Citrin 2017). In metastatic PPGL, this approach would have to be powered by various studies showing that indeed PPGL have specific 
immune targets since they are generally considered as immunogenically cold.

\section{New ligands or targets for PRRT}

More recently, there has been an evidence that radiolabeled SSTR2 antagonists generate higher tumor doses and more DNA double-strand breaks than agonists, resulting in better treatment efficacy despite poor internalization. An openlabel study to evaluate safety, tolerability, biodistribution, dosimetry and preliminary efficacy of ${ }^{177} \mathrm{Lu}-\mathrm{OPS} 201$ for the therapy of somatostatin receptor-positive NETs is currently recruiting patients (NCT02592707). In this clinical trial, malignant unresectable PHEO or PGL are also eligible.

An Evans blue (EB) modification of DOTA-octreotate, resulted in a radionuclide ${ }^{177} \mathrm{Lu}$-DOTA-EB-TATE which markedly increased binding to circulating serum albumin, a slower clearance through the urinary tract and thus, an increased half-life in blood was observed thereby increasing tumor retention. In a pilot study by Zhang et al. in advanced NET patients, ${ }^{177}$ Lu-DOTA-EB-TATE demonstrated a 7.9-fold increase in delivered tumor doses when comparable total body effective doses of ${ }^{177} \mathrm{Lu}$-DOTATATE $\quad(0.174 \quad$ millisievert/megabecquerel (mSv/MBq), three patients) and ${ }^{177} \mathrm{Lu}$-DOTA-EB-TATE (0.205 mSv/MBq, five patients) (Zhang et al. 2018). However, significant increase in dose delivery to the kidneys (3.2-fold) and bone marrow (18.2-fold) were noted in patients receiving ${ }^{177 \mathrm{Lu}-D O T A-E B-T A T E}$ than those receiving ${ }^{177} \mathrm{Lu}$-DOTATATE (Zhang et al. 2018). Subsequently, four NET patients were treated with single low-dose of ${ }^{177} \mathrm{Lu}$-DOTA-EB-TATE (0.66 gigabecquerel $(\mathrm{GBq})$ ) and were compared to a control group undergoing ${ }^{177} \mathrm{Lu}$-DOTATATE $(3.98 \mathrm{GBq}$, three patients) (Wang et al. 2018). The response was evaluated by assessing difference in $\mathrm{SUV}_{\max }$ of ${ }^{68} \mathrm{Ga}$-DOTATATE before and 3-month after therapy and no difference was found between ${ }^{177} \mathrm{Lu}$-DOTA-EB-TATE and ${ }^{177 \mathrm{Lu}-D O T A T A T E}$ groups. Further, the ${ }^{177} \mathrm{Lu}$-DOTA-EB-TATE group approximately received $1 / 6$ of the total radiation exposure compared to ${ }^{177} \mathrm{Lu}$-DOTATATE group. Also, single low-dose ${ }^{177} \mathrm{Lu}$-DOTAEB-TATE was found to be safe and effective in treatment of NETs. These encouraging results merit further studies with increasing dose and frequency of ${ }^{177} \mathrm{Lu}$-DOTA-EB-TATE in NETs, including PPGL.

With the expanding use of prostate-specific membrane antigen (PSMA)-based PET imaging, several reports have shown uptake in non-prostatic benign and malignant entities including PGL of urinary bladder in a patient with metastatic prostate cancer (Parihar et al. 2018). Since PSMA targeting represents a theranostic approach, it could be interesting to evaluate PSMA expression in a series of PPGLs with various genotypes.

In conclusion, nuclear medicine has gained an increasing role in the personalized approach to PPGL patients. This has been recently augmented by a number of excellent PET radiopharmaceuticals, which target different functional and molecular pathways that often reflect the diverse genetic landscape of PPGL. The visualization and quantification of tumor targets by imaging at the wholebody level (e.g. somatostatin receptors, norepinephrine transporter, and bone turnover), mirroring 'in vivo immunohistochemistry', enabling selection of candidates for potential targeted radionuclide therapy (Lutathera ${ }^{\circledR}$, Azedra ${ }^{\circledR}$, and Xofigo $\left.{ }^{\circledR}\right)$. The very recently obtained FDA approvals in this area have generated interest by various interest groups from researchers to industries and will give a new impetus to the development of therapeutic radiopharmaceuticals. Despite increased availability of diagnostic and therapeutic radiopharmaceuticals, it is important to remember that management of PPGL is complex and the patients should be referred to experienced centers for their management. The future of therapeutic nuclear medicine will also depend upon the identification of new targets, new schedules, and potential synergistic combinations.

\section{Declaration of interest}

The authors declare that there is no conflict of interest that could be perceived as prejudicing the impartiality of this review.

\section{Funding}

This research was supported, in part, by the Intramural Research Program of the National Institutes of Health, Eunice Kennedy Shriver National Institute of Child Health and Human Development.

\section{References}

Amar L, Bertherat J, Baudin E, Ajzenberg C, Bressac-de Paillerets B, Chabre O, Chamontin B, Delemer B, Giraud S, Murat A, et al. 2005 Genetic testing in pheochromocytoma or functional paraganglioma. Journal of Clinical Oncology 23 8812-8818. (https://doi.org/10.1200/ JCO.2005.03.1484)

Amar L, Baudin E, Burnichon N, Peyrard S, Silvera S, Bertherat J, Bertagna X, Schlumberger M, Jeunemaitre X, Gimenez-Roqueplo AP, et al. 2007 Succinate dehydrogenase B gene mutations predict survival in patients with malignant pheochromocytomas or paragangliomas. Journal of Clinical Endocrinology and Metabolism 92 3822-3828. (https://doi.org/10.1210/jc.2007-0709) (c) 2019 Society for Endocrinology Published by Bioscientifica Ltd. Printed in Great Britain 
Archier A, Varoquaux A, Garrigue P, Montava M, Guerin C, Gabriel S, Beschmout E, Morange I, Fakhry N, Castinetti F, et al. 2016 Prospective comparison of (68)Ga-DOTATATE and (18)F-FDOPA PET/ CT in patients with various pheochromocytomas and paragangliomas with emphasis on sporadic cases. European Journal of Nuclear Medicine and Molecular Imaging 43 1248-1257. (https://doi. org/10.1007/s00259-015-3268-2)

Ashwathanarayana AG, Biswal CK, Sood A, Parihar AS, Kapoor R \& Mittal BR 2017 Imaging-guided use of combined (177)Lu-DOTATATE and capecitabine therapy in metastatic mediastinal paraganglioma. Journal of Nuclear Medicine Technology 45 314-316. (https://doi. org/10.2967/jnmt.117.197400)

Ayala-Ramirez M, Feng L, Johnson MM, Ejaz S, Habra MA, Rich T, Busaidy N, Cote GJ, Perrier N, Phan A, et al. 2011 Clinical risk factors for malignancy and overall survival in patients with pheochromocytomas and sympathetic paragangliomas: primary tumor size and primary tumor location as prognostic indicators. Journal of Clinical Endocrinology and Metabolism 96 717-725. (https:// doi.org/10.1210/jc.2010-1946)

Ayala-Ramirez M, Palmer JL, Hofmann MC, de la Cruz M, Moon BS, Waguespack SG, Habra MA \& Jimenez C 2013 Bone metastases and skeletal-related events in patients with malignant pheochromocytoma and sympathetic paraganglioma. Journal of Clinical Endocrinology and Metabolism 98 1492-1497.

Baidoo KE, Yong K \& Brechbiel MW 2013 Molecular pathways: targeted $\alpha$-particle radiation therapy. Clinical Cancer Research 19 530-537. (https://doi.org/10.1158/1078-0432.CCR-12-0298)

Basu S, Ranade R \& Thapa P 2016 Metastatic neuroendocrine tumor with extensive bone marrow involvement at diagnosis: evaluation of response and hematological toxicity profile of PRRT with (177) Lu-DOTATATE. World Journal of Nuclear Medicine 15 38-43. (https:// doi.org/10.4103/1450-1147.165353)

Baum RP, Kulkarni HR, Singh A, Kaemmerer D, Mueller D, Prasad V, Hommann M, Robiller FC, Niepsch K, Franz H, et al. 2018 Results and adverse events of personalized peptide receptor radionuclide therapy with (90)Yttrium and (177)Lutetium in 1048 patients with neuroendocrine neoplasms. Oncotarget 9 16932-16950. (https://doi. org/10.18632/oncotarget.24524)

Benn DE, Gimenez-Roqueplo AP, Reilly JR, Bertherat J, Burgess J, Byth K, Croxson M, Dahia PL, Elston M, Grimm O, et al. 2006 Clinical presentation and penetrance of pheochromocytoma/paraganglioma syndromes. Journal of Clinical Endocrinology and Metabolism 91 827836. (https://doi.org/10.1210/jc.2005-1862)

Benn DE, Robinson BG \& Clifton-Bligh RJ 201515 YEARS OF PARAGANGLIOMA: Clinical manifestations of paraganglioma syndromes types 1-5. Endocrine-Related Cancer 22 T91-T103. (https:// doi.org/10.1530/ERC-15-0268)

Bergsma H, Konijnenberg MW, Kam BL, Teunissen JJ, Kooij PP, de Herder WW, Franssen GJ, van Eijck CH, Krenning EP \& Kwekkeboom DJ $2016 a$ Subacute haematotoxicity after PRRT with (177)Lu-DOTA-octreotate: prognostic factors, incidence and course. European Journal of Nuclear Medicine \& Molecular Imaging 43 453-463. (https://doi.org/10.1007/s00259-015-3193-4)

Bergsma H, Konijnenberg MW, van der Zwan WA, Kam BL, Teunissen JJ, Kooij PP, Mauff KA, Krenning EP \& Kwekkeboom DJ $2016 b$ Nephrotoxicity after PRRT with (177)Lu-DOTA-octreotate. European Journal of Nuclear Medicine \& Molecular Imaging 43 1802-1811. (https://doi.org/10.1007/s00259-016-3382-9)

Bergsma H, van Lom K, Raaijmakers MHGP, Konijnenberg M, Kam BLBLR, Teunissen JJM, de Herder WW, Krenning EP \& Kwekkeboom DJ 2018 Persistent hematologic dysfunction after peptide receptor radionuclide therapy with (177)Lu-DOTATATE: incidence, course, and predicting factors in patients with gastroenteropancreatic neuroendocrine tumors. Journal of Nuclear Medicine 59 452-458. (https://doi.org/10.2967/ jnumed.117.189712)
Black JRM, Atkinson SR, Singh A, Evans J \& Sharma R 2019 The inflammation-based index can predict response and improve patient selection in NETs treated with PRRT: a pilot study. Journal of Clinical Endocrinology \& Metabolism 104 285-292. (https://doi.org/10.1210/ jc.2018-01214)

Bodei L, Cremonesi M, Ferrari M, Pacifici M, Grana CM, Bartolomei M, Baio SM, Sansovini M \& Paganelli G 2008 Long-term evaluation of renal toxicity after peptide receptor radionuclide therapy with 90Y-DOTATOC and 177Lu-DOTATATE: the role of associated risk factors. European Journal of Nuclear Medicine \& Molecular Imaging 35 1847-1856. (https://doi.org/10.1007/s00259-008-0778-1)

Bodei L, Cremonesi M, Kidd M, Grana CM, Severi S, Modlin IM \& Paganelli G 2014a Peptide receptor radionuclide therapy for advanced neuroendocrine tumors. Thoracic Surgery Clinics 24333 349. (https://doi.org/10.1016/j.thorsurg.2014.04.005)

Bodei L, Cremonesi M \& Paganelli G 2014b Yttrium-based therapy for neuroendocrine tumors. PET Clinics 9 71-82. (https://doi. org/10.1016/j.cpet.2013.10.001)

Bodei L, Kidd M, Paganelli G, Grana CM, Drozdov I, Cremonesi M, Lepensky C, Kwekkeboom DJ, Baum RP, Krenning EP, et al. 2015 a Long-term tolerability of PRRT in 807 patients with neuroendocrine tumours: the value and limitations of clinical factors. European Journal of Nuclear Medicine and Molecular Imaging 42 5-19. (https:// doi.org/10.1007/s00259-014-2893-5)

Bodei L, Kidd M, Prasad V \& Modlin IM $2015 b$ Peptide receptor radionuclide therapy of neuroendocrine tumors. Frontiers of Hormone Research 44 198-215. (https://doi.org/10.1159/000402936)

Bodei L, Modlin IM, Luster M, Forrer F, Cremonesi M, Hicks RJ, Ezziddin S, Kidd M \& Chiti A 2016 Myeloid neoplasms after chemotherapy and PRRT: myth and reality. Endocrine-Related Cancer 23 C1-C7. (https://doi.org/10.1530/ERC-16-0258)

Bodei L, Kidd MS, Singh A, van der Zwan WA, Severi S, Drozdov IA, Cwikla J, Baum RP, Kwekkeboom DJ, Paganelli G, et al. 2018 PRRT genomic signature in blood for prediction of (177)Lu-octreotate efficacy. European Journal of Nuclear Medicine and Molecular Imaging 45 1155-1169. (https://doi.org/10.1007/s00259-018-3967-6)

Brabander T, van der Zwan WA, Teunissen JJM, Kam BLR, Feelders RA, de Herder WW, van Eijck CHJ, Franssen GJH, Krenning EP \& Kwekkeboom DJ 2017 Long-term efficacy, survival, and safety of [(177)Lu-DOTA(0),Tyr(3)]octreotate in patients with gastroenteropancreatic and bronchial neuroendocrine tumors. Clinical Cancer Research 23 4617-4624. (https://doi. org/10.1158/1078-0432.CCR-16-2743)

Breen W, Bancos I, Young WF, Jr, Bible KC, Laack NN, Foote RL \& Hallemeier CL 2018 External beam radiation therapy for advanced/ unresectable malignant paraganglioma and pheochromocytoma. Advances in Radiation Oncology 3 25-29. (https://doi.org/10.1016/j. adro.2017.11.002)

Brouwers FM, Eisenhofer G, Tao JJ, Kant JA, Adams KT, Linehan WM \& Pacak K 2006 High frequency of SDHB germline mutations in patients with malignant catecholamine-producingparagangliomas: implications for genetic testing. Journal of Clinical Endocrinology and Metabolism 91 4505-4509. (https://doi.org/10.1210/jc.2006-0423)

Carrasquillo JA, Pandit-Taskar N \& Chen CC 2016 I-131 metaiodobenzylguanidine therapy of pheochromocytoma and paraganglioma. Seminars in Nuclear Medicine 46 203-214. (https:// doi.org/10.1053/j.semnuclmed.2016.01.011)

Casey RT, Warren AY, Martin JE, Challis BG, Rattenberry E, Whitworth J, Andrews KA, Roberts T, Clark GR, West H, et al. 2017 Clinical and molecular features of renal and pheochromocytoma/paraganglioma tumor association syndrome (RAPTAS): case series and literature review. Journal of Clinical Endocrinology \& Metabolism $1024013-4022$. (https://doi.org/10.1210/jc.2017-00562)

Castro-Vega LJ, Buffet A, De Cubas AA, Cascon A, Menara M, Khalifa E, Amar L, Azriel S, Bourdeau I, Chabre O, et al. 2014 Germline mutations in $\mathrm{FH}$ confer predisposition to malignant 
pheochromocytomas and paragangliomas. Human Molecular Genetics 23 2440-2446. (https://doi.org/10.1093/hmg/ddt639)

Chang CA, Pattison DA, Tothill RW, Kong G, Akhurst TJ, Hicks RJ \& Hofman MS 2016 (68)Ga-DOTATATE and (18)F-FDG PET/CT in paraganglioma and pheochromocytoma: utility, patterns and heterogeneity. Cancer Imaging 16 22. (https://doi.org/10.1186/ s40644-016-0084-2)

Chauhan A, Horn M, Magee G, Hodges K, Evers M, Arnold S \& Anthony L 2018 Immune checkpoint inhibitors in neuroendocrine tumors: a single institution experience with review of literature. Oncotarget 9 8801-8809. (https://doi.org/10.18632/oncotarget.23753)

Cherk MH, Kong G, Hicks RJ \& Hofman MS 2018 Changes in biodistribution on 68Ga-DOTA-Octreotate PET/CT after long acting somatostatin analogue therapy in neuroendocrine tumour patients may result in pseudoprogression. Cancer Imaging 18 3. (https://doi. org/10.1186/s40644-018-0136-x)

Cistaro A, Quartuccio N, Caobelli F, Piccardo A, Paratore R, Coppolino P, Sperandeo A, Arnone G \& Ficola U 2015 124I-MIBG: a new promising positron-emitting radiopharmaceutical for the evaluation of neuroblastoma. Nuclear Medicine Review 18 102-106. (https://doi. org/10.5603/NMR.2015.0024)

Citrin DE 2017 Recent developments in radiotherapy. New England Journal of Medicine 377 1065-1075. (https://doi.org/10.1056/ NEJMra1608986)

Cives M, Strosberg J, Al Diffalha S \& Coppola D 2019 Analysis of the immune landscape of small bowel neuroendocrine tumors. Endocrine-Related Cancer 26 119-130. (https://doi.org/10.1530/ERC18-0189)

Cremonesi M, Ferrari ME, Bodei L, Chiesa C, Sarnelli A, Garibaldi C, Pacilio M, Strigari L, Summers PE, Orecchia R, et al. 2018 Correlation of dose with toxicity and tumour response to (90)Y- and (177) Lu-PRRT provides the basis for optimization through individualized treatment planning. European Journal of Nuclear Medicine and Molecular Imaging 45 2426-2441. (https://doi.org/10.1007/s00259018-4044-x)

Crona J, Taieb D \& Pacak K 2017 New perspectives on pheochromocytoma and paraganglioma: toward a molecular classification. Endocrine Reviews 38 489-515. (https://doi. org/10.1210/er.2017-00062)

Crona J, Lamarca A, Ghosal S, Welin S, Skogseid B \& Pacak K 2019 Genotype-phenotype correlations in pheochromocytoma and paraganglioma. Endocrine-Related Cancer 26 539-550. (https://doi. org/10.1530/ERC-19-0024)

Dahia PL 2014 Pheochromocytoma and paraganglioma pathogenesis: learning from genetic heterogeneity. Nature Reviews. Cancer 14108 119. (https://doi.org/10.1038/nrc3648)

Darr R, Nambuba J, Del Rivero J, Janssen I, Merino M, Todorovic M, Balint B, Jochmanova I, Prchal JT, Lechan RM, et al. 2016 Novel insights into the polycythemia-paraganglioma-somatostatinoma syndrome. Endocrine-Related Cancer 23 899-908. (https://doi. org/10.1530/ERC-16-0231)

Del Prete M, Buteau FA \& Beauregard JM 2017 Personalized (177) Lu-octreotate peptide receptor radionuclide therapy of neuroendocrine tumours: a simulation study. European Journal of Nuclear Medicine and Molecular Imaging 44 1490-1500. (https://doi. org/10.1007/s00259-017-3688-2)

Del Prete M, Arsenault F, Saighi N, Zhao W, Buteau FA, Celler A \& Beauregard JM 2018 Accuracy and reproducibility of simplified QSPECT dosimetry for personalized (177)Lu-octreotate PRRT. EJNMMI Physics 5 25. (https://doi.org/10.1186/s40658-018-0224-9)

Delpassand ES, Samarghandi A, Zamanian S, Wolin EM, Hamiditabar M, Espenan GD, Erion JL, O'Dorisio TM, Kvols LK, Simon J, et al. 2014 Peptide receptor radionuclide therapy with 177Lu-DOTATATE for patients with somatostatin receptor-expressing neuroendocrine tumors: the first US phase 2 experience. Pancreas 43 518-525. (https://doi.org/10.1097/MPA.0000000000000113)
Eisenhofer G, Lenders JW, Linehan WM, Walther MM, Goldstein DS \& Keiser HR 1999 Plasma normetanephrine and metanephrine for detecting pheochromocytoma in von Hippel-Lindau disease and multiple endocrine neoplasia type 2. New England Journal of Medicine 340 1872-1879. (https://doi.org/10.1056/NEJM199906173402404)

Eisenhofer G, Pacak K, Huynh TT, Qin N, Bratslavsky G, Linehan WM, Mannelli M, Friberg P, Grebe SK, Timmers HJ, et al. 2011 Catecholamine metabolomic and secretory phenotypes in phaeochromocytoma. Endocrine-Related Cancer 18 97-111. (https:// doi.org/10.1677/ERC-10-0211)

Estevao R, Duarte H, Lopes F, Fernandes J \& Monteiro E 2015 Peptide receptor radionuclide therapy in head and neck paragangliomas Report of 14 cases. Revue de Laryngologie - Otologie - Rhinologie 136 155-158.

Ezziddin S, Attassi M, Yong-Hing CJ, Ahmadzadehfar H, Willinek W, Grunwald F, Guhlke S, Biersack HJ \& Sabet A 2014 Predictors of long-term outcome in patients with well-differentiated gastroenteropancreatic neuroendocrine tumors after peptide receptor radionuclide therapy with $177 \mathrm{Lu}$-octreotate. Journal of Nuclear Medicine 55 183-190. (https://doi.org/10.2967/jnumed.113.125336)

Favier J, Amar L \& Gimenez-Roqueplo AP 2015 Paraganglioma and phaeochromocytoma: from genetics to personalized medicine. Nature Reviews. Endocrinology 11 101-111. (https://doi.org/10.1038/ nrendo.2014.188)

Fishbein L, Leshchiner I, Walter V, Danilova L, Robertson AG, Johnson AR, Lichtenberg TM, Murray BA, Ghayee HK, Else T, et al. 2017 Comprehensive molecular characterization of pheochromocytoma and paraganglioma. Cancer Cell 31 181-193. (https://doi.org/10.1016/j.ccell.2017.01.001)

Fonte JS, Robles JF, Chen CC, Reynolds J, Whatley M, Ling A, MercadoAsis LB, Adams KT, Martucci V, Fojo T, et al. 2012 False-negative 123I-MIBG SPECT is most commonly found in SDHB-related pheochromocytoma or paraganglioma with high frequency to develop metastatic disease. Endocrine-Related Cancer 19 83-93. (https://doi.org/10.1530/ERC-11-0243)

Forrer F, Riedweg I, Maecke HR \& Mueller-Brand J 2008 Radiolabeled DOTATOC in patients with advanced paraganglioma and pheochromocytoma. Quarterly Journal of Nuclear Medicine and Molecular Imaging 52 334-340.

Gabriel M, Nilica B, Kaiser B \& Virgolini IJ 2019 Twelve-year follow-up after peptide receptor radionuclide therapy. Journal of Nuclear Medicine 60 524-529. doi:10.2967/jnumed.118.215376.

Galluzzi L, Chan TA, Kroemer G, Wolchok JD \& Lopez-Soto A 2018 The hallmarks of successful anticancer immunotherapy. Science Translational Medicine 10 eaat7807. (https://doi.org/10.1126/ scitranslmed.aat7807)

Garcia-Carbonero R, Garcia-Figueiras R, Carmona-Bayonas A, Sevilla I, Teule A, Quindos M, Grande E, Capdevila J, Aller J, Arbizu J, et al. 2015 Imaging approaches to assess the therapeutic response of gastroenteropancreatic neuroendocrine tumors (GEP-NETs): current perspectives and future trends of an exciting field in development. Cancer Metastasis Reviews 34 823-842. (https://doi.org/10.1007/ s10555-015-9598-5)

Gild ML, Naik N, Hoang J, Hsiao E, McGrath RT, Sywak M, Sidhu S, Delbridge LW, Robinson BG, Schembri G, et al. 2018 Role of DOTATATE-PET/CT in preoperative assessment of phaeochromocytoma and paragangliomas. Clinical Endocrinology 89 139-147. (https://doi.org/10.1111/cen.13737)

Gimenez-Roqueplo AP, Favier J, Rustin P, Rieubland C, Crespin M, Nau V, Khau Van Kien P, Corvol P, Plouin PF \& Jeunemaitre X 2003 Mutations in the SDHB gene are associated with extra-adrenal and/ or malignant pheochromocytomas. Cancer Research 63 5615-5621.

Gonias S, Goldsby R, Matthay KK, Hawkins R, Price D, Huberty J, Damon L, Linker C, Sznewajs A, Shiboski S, et al. 2009 Phase II study of high-dose [131I] metaiodobenzylguanidine therapy for patients with metastatic pheochromocytoma and paraganglioma. https://erc bioscientifica.com

https://doi.org/10.1530/ERC-19-0165 c) 2019 Society for Endocrinology Published by Bioscientifica Ltd. Printed in Great Britain 
Journal of Clinical Oncology 27 4162-4168. (https://doi.org/10.1200/ JCO.2008.21.3496)

Gupta SK, Singla S, Karunanithi S, Damle N \& Bal C 2014 Peptide receptor radionuclide therapy with (177)Lu DOTATATE in a case of recurrent carotid body paraganglioma with spinal metastases. Clinical Nuclear Medicine 39 440-441. (https://doi.org/10.1097/ RLU.0000000000000273)

Hadoux J, Favier J, Scoazec JY, Leboulleux S, Al Ghuzlan A, Caramella C, Deandreis D, Borget I, Loriot C, Chougnet C, et al. 2014 SDHB mutations are associated with response to temozolomide in patients with metastatic pheochromocytoma or paraganglioma. International Journal of Cancer 135 2711-2720. (https://doi.org/10.1002/ijc.28913)

Hamidi O, Young WF Jr, Iniguez-Ariza NM, Kittah NE, Gruber L, Bancos C, Tamhane S \& Bancos I 2017 Malignant pheochromocytoma and paraganglioma: 272 patients over 55 years. Journal of Clinical Endocrinology and Metabolism 102 3296-3305. (https://doi.org/10.1210/jc.2017-00992)

Han S, Suh CH, Woo S, Kim YJ \& Lee JJ 2019 Performance of (68) Ga-DOTA-conjugated somatostatin receptor targeting peptide PET in detection of pheochromocytoma and paraganglioma: a systematic review and meta-analysis. Journal of Nuclear Medicine 60 369-376. (https://doi.org/10.2967/jnumed.118.211706)

Hartung-Knemeyer V, Rosenbaum-Krumme S, Buchbender C, Pöppel T, Brandau W, Jentzen W, Antoch G, Forsting M, Bockisch A, Kühl H, et al. 2012 Malignant pheochromocytoma imaging with [124I]mIBG PET/MR. Journal of Clinical Endocrinology and Metabolism 97 3833-3834.

Hendifar AE, Delpassand ES, Kittleson MM \& Tuli R 2018 Cardiac toxicity in a patient receiving peptide receptor radionuclide therapy. Pancreas 47 e55-e56. (https://doi.org/10.1097/ MPA.0000000000001101)

Hescot S, Curras-Freixes M, Deutschbein T, van Berkel A, Vezzosi D, Amar L, de la Fouchardière C, Valdes N, Riccardi F, Do Cao C, et al. 2019 Prognosis of malignant pheochromocytoma and paraganglioma (MAPP-prono study): a European network for the study of adrenal tumors retrospective study. Journal of Clinical Endocrinology \& Metabolism 104 2367-2374. (https://doi.org/10.1210/jc.2018-01968)

Hofman MS \& Hicks RJ 2015 Moving beyond "Lumpology": PET/CT imaging of pheochromocytoma and paraganglioma. Clinical Cancer Research 21 3815-3817. (https://doi.org/10.1158/1078-0432.CCR-151073)

Hofman MS, Lau WF \& Hicks RJ 2015 Somatostatin receptor imaging with 68Ga DOTATATE PET/CT: clinical utility, normal patterns, pearls, and pitfalls in interpretation. Radiographics 35 500-516. (https://doi.org/10.1148/rg.352140164)

Huizing DMV, de Wit-van der Veen BJ, Verheij M \& Stokkel MPM 2018 Dosimetry methods and clinical applications in peptide receptor radionuclide therapy for neuroendocrine tumours: a literature review. EJNMMI Research 8 89. (https://doi.org/10.1186/s13550-018-0443-z)

Imhof A, Brunner P, Marincek N, Briel M, Schindler C, Rasch H, Mäcke HR, Rochlitz C, Müller-Brand J \& Walter MA 2011 Response, survival, and long-term toxicity after therapy with the radiolabeled somatostatin analogue [90Y-DOTA]-TOC in metastasized neuroendocrine cancers. Journal of Clinical Oncology 29 2416-2423 (https://doi.org/10.1200/JCO.2010.33.7873).

Jafri M, Whitworth J, Rattenberry E, Vialard L, Kilby G, Kumar AV, Izatt L, Lalloo F, Brennan P, Cook J, et al. 2013 Evaluation of SDHB, SDHD and VHL gene susceptibility testing in the assessment of individuals with non-syndromic phaeochromocytoma, paraganglioma and head and neck paraganglioma. Clinical Endocrinology 78 898-906. (https://doi.org/10.1111/cen.12074)

Janssen I, Blanchet EM, Adams K, Chen CC, Millo CM, Herscovitch P, Taieb D, Kebebew E, Lehnert H, Fojo AT, et al. 2015 Superiority of [68Ga]-DOTATATE PET/CT to other functional imaging modalities in the localization of SDHB-associated metastatic pheochromocytoma and paraganglioma. Clinical Cancer Research 21 3888-3895. (https:// doi.org/10.1158/1078-0432.CCR-14-2751)
Janssen I, Chen CC, Millo CM, Ling A, Taieb D, Lin FI, Adams KT, Wolf KI, Herscovitch P, Fojo AT, et al. 2016a PET/CT comparing (68) Ga-DOTATATE and other radiopharmaceuticals and in comparison with CT/MRI for the localization of sporadic metastatic pheochromocytoma and paraganglioma. European Journal of Nuclear Medicine and Molecular Imaging 43 1784-1791. (https://doi. org/10.1007/s00259-016-3357-x)

Janssen I, Chen CC, Taieb D, Patronas NJ, Millo CM, Adams KT, Nambuba J, Herscovitch P, Sadowski SM, Fojo AT, et al. $2016 b$ 68Ga-DOTATATE PET/CT in the localization of head and neck paragangliomas compared with other functional imaging modalities and CT/MRI. Journal of Nuclear Medicine 57 186-191. (https://doi. org/10.2967/jnumed.115.161018)

Janssen I, Chen CC, Zhuang Z, Millo CM, Wolf KI, Ling A, Lin FI, Adams KT, Herscovitch P, Feelders RA, et al. 2017 Functional imaging signature of patients presenting with polycythemia/paraganglioma syndromes. Journal of Nuclear Medicine 58 1236-1242. (https://doi. org/10.2967/jnumed.116.187690)

Jha A, Ling A, Millo C, Chen C, Gupta G, Viana B, Gonzales M, Adams K, Herscovitch P, Lin F, et al. 2018a Superiority of 68Ga-DOTATATE PET/CT to other functional and anatomic imaging modalities in the detection of SDHD-related pheochromocytoma and paraganglioma - A comparative prospective study. Journal of Nuclear Medicine 59 46-46.

Jha A, Ling A, Millo C, Gupta G, Viana B, Lin FI, Herscovitch P, Adams KT, Taieb D, Metwalli AR, et al. 2018b Superiority of (68) Ga-DOTATATE over (18)F-FDG and anatomic imaging in the detection of succinate dehydrogenase mutation (SDHx )-related pheochromocytoma and paraganglioma in the pediatric population. European Journal of Nuclear Medicine and Molecular Imaging 45 787797. (https://doi.org/10.1007/s00259-017-3896-9)

Jha A, de Luna K, Balili CA, Millo C, Paraiso CA, Ling A, Gonzales MK, Viana B, Alrezk R, Adams KT, et al. 2019a Clinical, diagnostic, and treatment characteristics of SDHA-related metastatic pheochromocytoma and paraganglioma. Frontiers in Oncology 953. (https://doi.org/10.3389/fonc.2019.00053)

Jha A, Ling A, Millo C, Chen C, Gonzales M, Patel M, Tena I, Mamilla D, Knue M, Geraldine O'Sullivan C, et al. 2019b Diagnostic performance of PET/CT utilizing 68Ga-DOTATATE, 18F-FDG, 18F-DOPA, and 18F-FDA, and anatomic imaging in the detection of sporadic primary pheochromocytoma - A comparative prospective study. Journal of Nuclear Medicine 60439.

Jochmanova I \& Pacak K 2018 Genomic landscape of pheochromocytoma and paraganglioma. Trends in Cancer 4 6-9. (https://doi.org/10.1016/j.trecan.2017.11.001)

Kan Y, Zhang S, Wang W, Liu J, Yang J \& Wang Z 2018 (68) Ga-somatostatin receptor analogs and (18)F-FDG PET/CT in the localization of metastatic pheochromocytomas and paragangliomas with germline mutations: a meta-analysis. Acta Radiologica 59 14661474. (https://doi.org/10.1177/0284185118764206)

Kelkar SS \& Reineke TM 2011 Theranostics: combining imaging and therapy. Bioconjugate Chemistry 22 1879-1903. (https://doi. org/10.1021/bc200151q)

Kesavan M, Claringbold PG \& Turner JH 2014 Hematological toxicity of combined $177 \mathrm{Lu}$-octreotate radiopeptide chemotherapy of gastroenteropancreatic neuroendocrine tumors in long-term follow-up. Neuroendocrinology 99 108-117. (https://doi. org/10.1159/000362558)

Kesavan M \& Turner JH 2016 Myelotoxicity of peptide receptor radionuclide therapy of neuroendocrine tumors: a decade of experience. Cancer Biotherapy \& Radiopharmaceuticals 31 189-198. (https://doi.org/10.1089/cbr.2016.2035)

King KS, Prodanov T, Kantorovich V, Fojo T, Hewitt JK, Zacharin M, Wesley R, Lodish M, Raygada M, Gimenez-Roqueplo AP, et al. 2011 Metastatic pheochromocytoma/paraganglioma related to primary tumor development in childhood or adolescence: significant link to 
SDHB mutations. Journal of Clinical Oncology 29 4137-4142. (https:// doi.org/10.1200/JCO.2011.34.6353)

Kolasinska-Cwikla A, Peczkowska M, Cwikla JB, Michalowska I, Palucki JM, Bodei L, Lewczuk-Myslicka A \& Januszewicz A 2019 A clinical efficacy of PRRT in patients with advanced, nonresectable, paraganglioma-pheochromocytoma, related to SDHx gene mutation. Journal of Clinical Medicine 8 952. (https://doi.org/10.3390/ jcm8070952)

Kong G, Grozinsky-Glasberg S, Hofman MS, Callahan J, Meirovitz A, Maimon O, Pattison DA, Gross DJ \& Hicks RJ 2017 Efficacy of peptide receptor radionuclide therapy for functional metastatic paraganglioma and pheochromocytoma. Journal of Clinical Endocrinology \& Metabolism 102 3278-3287. (https://doi.org/10.1210/ jc.2017-00816)

Kong G, Schenberg T, Yates CJ, Trainer A, Sachithanandan N, Iravani A, Ravi Kumar A, Hofman MS, Akhurst T, Michael M, et al. 2019 The role of 68Ga-DOTA-Octreotate (GaTate) PET/CT in follow-up of SDHassociated pheochromocytoma and paraganglioma (PPGL). Journal of Clinical Endocrinology \& Metabolism 104 5091-5099. (https://doi. org/10.1210/jc.2019-00018)

Kratochwil C, Lopez-Benitez R, Mier W, Haufe S, Isermann B, Kauczor HU, Choyke PL, Haberkorn U \& Giesel FL 2011 Hepatic arterial infusion enhances DOTATOC radiopeptide therapy in patients with neuroendocrine liver metastases. Endocrine-Related Cancer 18 595-602. (https://doi.org/10.1530/ERC-11-0144)

Kratochwil C, Giesel FL, Bruchertseifer F, Mier W, Apostolidis C, Boll, Murphy K, Haberkorn U \& Morgenstern A 2014 213Bi-DOTATOC receptor-targeted alpha-radionuclide therapy induces remission in neuroendocrine tumours refractory to beta radiation: a first-inhuman experience. European Journal of Nuclear Medicine and Molecular Imaging 41 2106-2119. (https://doi.org/10.1007/s00259014-2857-9)

Kroiss A, Putzer D, Frech A, Decristoforo C, Uprimny C, Gasser RW, Shulkin BL, Url C, Widmann G, Prommegger R, et al. 2013 A retrospective comparison between 68Ga-DOTA-TOC PET/CT and 18F-DOPA PET/CT in patients with extra-adrenal paraganglioma. European Journal of Nuclear Medicine and Molecular Imaging 40 1800-1808.

Kroiss A, Shulkin BL, Uprimny C, Frech A, Gasser RW, Url C, Gautsch K, Madleitner R, Nilica B, Sprinzl GM, et al. 2015 (68)Ga-DOTATOC $\mathrm{PET} / \mathrm{CT}$ provides accurate tumour extent in patients with extraadrenal paraganglioma compared to (123)I-MIBG SPECT/CT. European Journal of Nuclear Medicine and Molecular Imaging 42 33-41.

Kumar V, Gu Y, Basu S, Berglund A, Eschrich SA, Schabath MB, Forster K, Aerts HJ, Dekker A, Fenstermacher D, et al. 2012 Radiomics: the process and the challenges. Magnetic Resonance Imaging 30 1234-1248. (https://doi.org/10.1016/j.mri.2012.06.010)

Lambin P, Rios-Velazquez E, Leijenaar R, Carvalho S, van Stiphout RG, Granton P, Zegers CM, Gillies R, Boellard R, Dekker A, et al. 2012 Radiomics: extracting more information from medical images using advanced feature analysis. European Journal of Cancer 48 441-446. (https://doi.org/10.1016/j.ejca.2011.11.036)

Lawrence MS, Stojanov P, Polak P, Kryukov GV, Cibulskis K, Sivachenko A, Carte SL, Stewart C, Mermel CH, Roberts SA, et al. 2013 Mutational heterogeneity in cancer and the search for new cancer-associated genes. Nature 499 214-218. (https://doi. org/10.1038/nature12213)

Makis W, McCann K, McEwan AJ \& Sawyer MB 2016 Palliation of extensive metastatic bone disease with 223Ra-dichloride alphaparticle therapy in a patient with malignant hereditary paraganglioma-pheochromocytoma syndrome with SDHB mutation. Clinical Nuclear Medicine 41 144-147. (https://doi.org/10.1097/ RLU.0000000000000964)

Mei L, Khurana A, Al-Juhaishi T, Faber A, Celi F, Smith S \& Boikos S 2019 Prognostic factors of malignant pheochromocytoma and paraganglioma: a combined SEER and TCGA databases review.
Hormone and Metabolic Research 51 451-457. (https://doi. org/10.1055/a-0851-3275)

Naji M, Zhao C, Welsh SJ, Meades R, Win Z, Ferrarese A, Tan T, Rubello D \& Al-Nahhas A 2011 68Ga-DOTA-TATE PET vs. 123I-MIBG in identifying malignant neural crest tumours. Molecular Imaging and Biology 13 769-775. (https://doi.org/10.1007/s11307-010-0396-8)

Nambuba J, Därr R, Janssen I, Bullova P, Adams KT, Millo C, Bourdeau I, Kassai A, Yang C, Kebebew E, et al. 2016 Functional imaging experience in a germline fumarate hydratase mutation-positive patient with pheochromocytoma and paraganglioma. AACE Clinical Case Reports 2 e176-e181. (https://doi.org/10.4158/EP15759.CR)

Nastos K, Cheung VTF, Toumpanakis C, Navalkissoor S, Quigley AM, Caplin M \& Khoo B 2017 Peptide receptor radionuclide treatment and (131)I-MIBG in the management of patients with metastatic/ progressive phaeochromocytomas and paragangliomas. Journal of Surgical Oncology 115 425-434. (https://doi.org/10.1002/jso.24553)

Navalkissoor S \& Grossman A 2019 Targeted alpha particle therapy for neuroendocrine tumours: the next generation of peptide receptor radionuclide therapy. Neuroendocrinology 108 256-264. (https://doi. org/10.1159/000494760)

Neumann HP, Pawlu C, Peczkowska M, Bausch B, McWhinney SR, Muresan M, Buchta M, Franke G, Klisch J, Bley TA, et al. 2004 Distinct clinical features of paraganglioma syndromes associated with SDHB and SDHD gene mutations. JAMA 292 943-951. (https:// doi.org/10.1001/jama.292.8.943)

Neumann HP, Erlic Z, Boedeker CC, Rybicki LA, Robledo M, Hermsen M, Schiavi F, Falcioni M, Kwok P, Bauters C, et al. 2009 Clinical predictors for germline mutations in head and neck paraganglioma patients: cost reduction strategy in genetic diagnostic process as fallout. Cancer Research 69 3650-3656. (https://doi.org/10.1158/00085472.CAN-08-4057)

Neumann HP, Young WF Jr, Krauss T, Bayley JP, Schiavi F, Opocher G, Boedeker CC, Tirosh A, Castinetti F, Ruf J, et al. 201865 YEARS OF THE DOUBLE HELIX: Genetics informs precision practice in the diagnosis and management of pheochromocytoma. Endocrine-Related Cancer 25 T201-T219. (https://doi.org/10.1530/ERC-18-0085)

Niemeijer ND, Alblas G, van Hulsteijn LT, Dekkers OM \& Corssmit EP 2014 Chemotherapy with cyclophosphamide, vincristine and dacarbazine for malignant paraganglioma and pheochromocytoma: systematic review and meta-analysis. Clinical Endocrinology 81642 651. (https://doi.org/10.1111/cen.12542)

Nolting S, Grossman A \& Pacak K 2019 Metastatic phaeochromocytoma: spinning Towards more promising treatment options. Experimental and Clinical Endocrinology \& Diabetes 127 117-128. (https://doi. org/10.1055/a-0715-1888)

O'Connor JPB, Rose CJ, Waterton JC, Carano RAD, Parker GJM \& Jackson A 2015 Imaging intratumor heterogeneity: role in therapy response, resistance, and clinical outcome. Clinical Cancer Research 21 249-257. (https://doi.org/10.1158/1078-0432.CCR-14-0990)

Ohshima Y, Sudo H, Watanabe S, Nagatsu K, Tsuji AB, Sakashita T, Ito YM, Yoshinaga K, Higashi T \& Ishioka NS 2018 Antitumor effects of radionuclide treatment using $\alpha$-emitting meta-211At-astatobenzylguanidine in a PC12 pheochromocytoma model. European Journal of Nuclear Medicine and Molecular Imaging 45 999-1010. (https://doi.org/10.1007/s00259-017-3919-6).

Oksuz MO, Winter L, Pfannenberg C, Reischl G, Mussig K, Bares R \& Dittmann H 2014 Peptide receptor radionuclide therapy of neuroendocrine tumors with (90)Y-DOTATOC: is treatment response predictable by pre-therapeutic uptake of (68)Ga-DOTATOC? Diagnostic and Interventional Imaging 95 289-300.

Pandit-Taskar N, Zanzonico P, Staton KD, Carrasquillo JA, ReidyLagunes D, Lyashchenko S, Burnazi E, Zhang H, Lewis JS, Blasberg R, et al. 2018 Biodistribution and dosimetry of (18) F-metafluorobenzylguanidine: a first-in-human PET/CT imaging study of patients with neuroendocrine malignancies. Journal of Nuclear Medicine 59 147-153. (https://doi.org/10.2967/jnumed.117.193169) https://erc bioscientifica com

https://doi.org/10.1530/ERC-19-0165 c) 2019 Society for Endocrinology Published by Bioscientifica Ltd. Printed in Great Britain 
Papathomas TG, Gaal J, Corssmit EP, Oudijk L, Korpershoek E, Heimdal K, Bayley JP, Morreau H, van Dooren M, Papaspyrou K, et al. 2014 Non-pheochromocytoma (PCC)/paraganglioma (PGL) tumors in patients with succinate dehydrogenase-related PCC-PGL syndromes: a clinicopathological and molecular analysis. European Journal of Endocrinology 170 1-12. (https://doi.org/10.1530/EJE-130623)

Parihar AS, Vadi SK, Mittal BR, Kumar R, Bal A \& Singh SK 2018 68Ga-PSMA-HBED-CC-avid synchronous urinary bladder paraganglioma in a patient with metastatic prostate carcinoma. Clinical Nuclear Medicine 43 e329-e330. (https://doi.org/10.1097/ RLU.0000000000002172)

Parker C, Nilsson S, Heinrich D, Helle SI, O'Sullivan JM, Fossa SD, Chodacki A, Wiechno P, Logue J, Seke M, et al. 2013 Alpha emitter radium-223 and survival in metastatic prostate cancer. New England Journal of Medicine 369 213-223. (https://doi.org/10.1056/ NEJMoa1213755)

Pasini B, McWhinney SR, Bei T, Matyakhina L, Stergiopoulos S, Muchow M, Boikos SA, Ferrando B, Pacak K, Assie G, et al. 2008 Clinical and molecular genetics of patients with the Carney-Stratakis syndrome and germline mutations of the genes coding for the succinate dehydrogenase subunits SDHB, SDHC, and SDHD. European Journal of Human Genetics 16 79-88. (https://doi. org/10.1038/sj.ejhg.5201904)

Pinato DJ, Black JR, Ramaswami R, Tan TM, Adjogatse D \& Sharma R 2016 Peptide receptor radionuclide therapy for metastatic paragangliomas. Medical Oncology 33 47. (https://doi.org/10.1007/ s12032-016-0737-9)

Plouin PF, Amar L, Dekkers OM, Fassnacht M, Gimenez-Roqueplo AP, Lenders JW, Lussey-Lepoutre C, Steichen O \& Guideline Working Group 2016 European Society of Endocrinology Clinical Practice Guideline for long-term follow-up of patients operated on for a phaeochromocytoma or a paraganglioma. European Journal of Endocrinology 174 G1-G10. (https://doi.org/10.1530/EJE-16-0033)

Pryma DA, Chin BB, Noto RB, Dillon JS, Perkins S, Solnes L, Kostakoglu L, Serafini AN, Pampaloni MH, Jensen J, et al. 2019 Efficacy and safety of high-specific-activity I-131 MIBG therapy in patients with advanced pheochromocytoma or paraganglioma. Journal of Nuclear Medicine 60 623-630. (https://doi.org/10.2967/ jnumed.118.217463).

Puranik AD, Kulkarni HR, Singh A \& Baum RP 2015 Peptide receptor radionuclide therapy with (90)Y/ (177)Lu-labelled peptides for inoperable head and neck paragangliomas (glomus tumours). European Journal of Nuclear Medicine and Molecular Imaging 421223 1230. (https://doi.org/10.1007/s00259-015-3029-2)

Ranade R \& Basu S 2016 177Lu-DOTATATE PRRT in patients with metastatic neuroendocrine tumor and a single functioning kidney: tolerability and effect on renal function. Journal of Nuclear Medicine and Technology 44 65-69.

Riff BP, Yang YX, Soulen MC, Pryma DA, Bennett B, Wild D, Nicolas G, Teitelbaum UR \& Metz DC 2015 Peptide receptor radionuclide therapy-induced hepatotoxicity in patients with metastatic neuroendocrine tumors. Clinical Nuclear Medicine 40 845-850. (https://doi.org/10.1097/RLU.0000000000000935)

Sabet A, Ezziddin K, Pape UF, Ahmadzadehfar H, Mayer K, Poppel T, Guhlke S, Biersack HJ \& Ezziddin S 2013a Long-term hematotoxicity after peptide receptor radionuclide therapy with $177 \mathrm{Lu}$-octreotate. Journal of Nuclear Medicine 54 1857-1861. (https://doi.org/10.2967/ jnumed.112.119347)

Sabet A, Khalaf F, Haslerud T, Al-Zreiqat A, Sabet A, Simon B, Poppel TD, Biersack HJ \& Ezziddin S 2013b Bone metastases in GEP-NET: response and long-term outcome after PRRT from a follow-up analysis. American Journal of Nuclear Medicine and Molecular Imaging $\mathbf{3}$ 437-445.

Sabet A, Ezziddin K, Pape UF, Reichman K, Haslerud T, Ahmadzadehfar H, Biersack HJ, Nagarajah J \& Ezziddin S 2014
Accurate assessment of long-term nephrotoxicity after peptide receptor radionuclide therapy with (177)Lu-octreotate. European Journal of Nuclear Medicine \& Molecular Imaging 41 505-510. (https:// doi.org/10.1007/s00259-013-2601-x)

Sandstrom M, Garske-Roman U, Granberg D, Johansson S, Widstrom C, Eriksson B, Sundin A, Lundqvist H \& Lubberink M 2013 Individualized dosimetry of kidney and bone marrow in patients undergoing 177Lu-DOTA-octreotate treatment. Journal of Nuclear Medicine 54 33-41. (https://doi.org/10.2967/jnumed.112.107524)

Schovanek J, Martucci V, Wesley R, Fojo T, Del Rivero J, Huynh T, Adams K, Kebebew E, Frysak Z, Stratakis CA, et al. 2014 The size of the primary tumor and age at initial diagnosis are independent predictors of the metastatic behavior and survival of patients with SDHB-related pheochromocytoma and paraganglioma: a retrospective cohort study. BMC Cancer 14 523. (https://doi. org/10.1186/1471-2407-14-523)

Serre R, Benzekry S, Padovani L, Meille C, Andre N, Ciccolini J, Barlesi F, Muracciole X \& Barbolosi D 2016 Mathematical modeling of cancer immunotherapy and its synergy with radiotherapy. Cancer Research 76 4931-4940. (https://doi.org/10.1158/0008-5472.CAN-15-3567)

Sharma P, Thakar A, Suman Kc S, Dhull VS, Singh H, Naswa N, Reddy RM, Karunanithi S, Kumar R, Kumar R, et al. 2013 68Ga-DOTANOC PET/CT for baseline evaluation of patients with head and neck paraganglioma. Journal of Nuclear Medicine $\mathbf{5 4} 841$ 847. (https://doi.org/10.2967/jnumed.112.115485)

Sharma P, Dhull VS, Arora S, Gupta P, Kumar R, Durgapal P, Malhotra A, Chumber S, Ammini AC, Kumar R, et al. 2014 Diagnostic accuracy of (68)Ga-DOTANOC PET/CT imaging in pheochromocytoma. European Journal of Nuclear Medicine and Molecular Imaging 41 494504. (https://doi.org/10.1007/s00259-013-2598-1)

Sharma P, Mukherjee A, Karunanithi S, Naswa N, Kumar R, Ammini AC \& Bal C 2015 Accuracy of 68Ga DOTANOC PET/CT imaging in patients with multiple endocrine neoplasia syndromes. Clinical Nuclear Medicine 40 e351-e356. (https://doi.org/10.1097/ RLU.0000000000000775)

Strosberg J, El-Haddad G, Wolin E, Hendifar A, Yao J, Chasen B, Mittra E, Kunz PL, Kulke MH, Jacene H, et al. 2017 Phase 3 trial of 177Lu-Dotatate for midgut neuroendocrine tumors. New England Journal of Medicine 376 125-135. (https://doi.org/10.1056/ NEJMoa1607427)

Strosberg J, Wolin E, Chasen B, Kulke M, Bushnell D, Caplin M, Baum RP, Kunz P, Hobday T, Hendifar A, et al. 2018 Health-related quality of life in patients with progressive midgut neuroendocrine tumors treated with (177)Lu-Dotatate in the Phase III NETTER-1 trial. Journal of Clinical Oncology 36 2578-2584. (https://doi. org/10.1200/JCO.2018.78.5865)

Suarez C, Rodrigo JP, Bodeker CC, Llorente JL, Silver CE, Jansen JC, Takes RP, Strojan P, Pellitteri PK, Rinaldo A, et al. 2013 Jugular and vagal paragangliomas: systematic study of management with surgery and radiotherapy. Head \& Neck 35 1195-1204. (https://doi. org/10.1002/hed.22976)

Sundlov A, Sjogreen-Gleisner K, Svensson J, Ljungberg M, Olsson T, Bernhardt P \& Tennvall J 2017 Individualised (177)Lu-DOTATATE treatment of neuroendocrine tumours based on kidney dosimetry. European Journal of Nuclear Medicine and Molecular Imaging 44 14801489. (https://doi.org/10.1007/s00259-017-3678-4)

Taieb D, Garrigue P, Bardies M, Abdullah AE \& Pacak K 2015 Application and dosimetric requirements for gallium-68-labeled somatostatin analogues in targeted radionuclide therapy for gastroenteropancreatic neuroendocrine tumors. PET Clinics 10477 486. (https://doi.org/10.1016/j.cpet.2015.06.001)

Taieb D, Hicks RJ \& Pacak K 2016 Nuclear medicine in cancer theranostics: Beyond the target. Journal of Nuclear Medicine 57 16591660. (https://doi.org/10.2967/jnumed.116.178343)

Taieb D, Jha A, Guerin C, Pang Y, Adams KT, Chen CC, Romanet P, Roche P, Essamet W, Ling A, et al. 2018 18F-FDOPA PET/CT imaging of 
MAX-related pheochromocytoma. Journal of Clinical Endocrinology \& Metabolism 103 1574-1582. (https://doi.org/10.1210/jc.2017-02324)

Taieb D, Hicks RJ, Hindie E, Guillet BA, Avrram A, Ghedini P, Timmers HJ, Scott AT, Elojjeimy S, Rubello D, et al. 2019 European Association of Nuclear Medicine Practice Guideline/Society of Nuclear Medicine and Molecular Imaging Procedure Standard 2019 for radionuclide imaging of phaeochromocytoma and paraganglioma. European Journal of Nuclear Medicine and Molecular Imaging 46 2112-2137. (https://doi.org/10.1007/s00259-019-04398-1)

Tan TH, Hussein Z, Saad FF \& Shuaib IL 2015 Diagnostic performance of (68) Ga-DOTATATE PET/CT, (18)F-FDG PET/CT and (131) I-MIBG scintigraphy in mapping metastatic pheochromocytoma and paraganglioma. Nuclear Medicine and Molecular Imaging 49 143-151.

Turkova H, Prodanov T, Maly M, Martucci V, Adams K, Widimsky J, Jr, Chen CC, Ling A, Kebebew E, Stratakis CA, et al. 2016 Characteristics and outcomes of metastatic Sdhb and sporadic pheochromocytoma/ paraganglioma: an National Institutes of Health study. Endocrine Practice 22 302-314. (https://doi.org/10.4158/EP15725.OR)

van Essen M, Krenning EP, Kooij PP, Bakker WH, Feelders RA, de Herder WW, Wolbers JG \& Kwekkeboom DJ 2006 Effects of therapy with [177Lu-DOTA0, Tyr3] octreotate in patients with paraganglioma, meningioma, small cell lung carcinoma, and melanoma. Journal of Nuclear Medicine 47 1599-1606.

van Hulsteijn LT, Niemeijer ND, Dekkers OM \& Corssmit EP 2014 (131) I-MIBG therapy for malignant paraganglioma and phaeochromocytoma: systematic review and meta-analysis. Clinical Endocrinology 80 487-501. (https://doi.org/10.1111/cen.12341)

Viglianti BL, Wale DJ, Wong KK, Johnson TD, Ky C, Frey KA \& Gross MD 2018 Effects of tumor burden on reference tissue standardized uptake for PET imaging: modification of PERCIST criteria. Radiology 287993 1002. (https://doi.org/10.1148/radiol.2018171356)

Vogel J, Atanacio AS, Prodanov T, Turkbey BI, Adams K, Martucci V, Camphausen K, Fojo AT, Pacak K \& Kaushal A 2014 External beam radiation therapy in treatment of malignant pheochromocytoma and paraganglioma. Frontiers in Oncology 4 166. (https://doi. org/10.3389/fonc.2014.00166)

Vyakaranam AR, Crona J, Norlen O, Granberg D, Garske-Roman U, Sandström M, Fröss-Baron K, Thiis-Evensen E, Hellman P \& Sundin A 2019 Favorable outcome in patients with pheochromocytoma and paraganglioma treated with 177Lu-DOTATATE. Cancers 11909. (https://doi.org/10.3390/cancers11070909)

Wadas TJ, Pandya DN, Solingapuram Sai KK \& Mintz A 2014 Molecular targeted alpha-particle therapy for oncologic applications. AJR. American Journal of Roentgenology 203 253-260. (https://doi. org/10.2214/AJR.14.12554)

Wang $\mathrm{H}$, Cheng Y, Zhang J, Zang J, Li H, Liu Q, Wang J, Jacobson O, Li F, Zhu Z, et al. 2018 Response to single low-dose 177Lu-DOTA-EBTATE treatment in patients with advanced neuroendocrine neoplasm: a prospective pilot study. Theranostics 8 3308-3316. (https://doi.org/10.7150/thno.25919)

Welander J, So"derkvist P \& Gimm O 2011 Genetics and clinical characteristics of hereditary pheochromocytomas and paragangliomas. Endocrine-Related Cancer 18 R253-R276. (https://doi. org/10.1530/ERC-11-0170)

Werner RA, Lapa C, Ilhan H, Higuchi T, Buck AK, Lehner S, Bartenstein P, Bengel F, Schatka I, Muegge DO, et al. 2017 Survival prediction in patients undergoing radionuclide therapy based on intratumoral somatostatin-receptor heterogeneity. Oncotarget 8 70397049. (https://doi.org/10.18632/oncotarget.12402).

Werner RA, Ilhan H, Lehner S, Papp L, Zsoter N, Schatka I, Muegge DO, Javadi MS, Higuchi T, Buck AK, et al. 2019 Pre-therapy somatostatin receptor-based heterogeneity predicts overall survival in pancreatic neuroendocrine tumor patients undergoing peptide receptor radionuclide therapy. Molecular Imaging \& Biology 21 582-590. (https://doi.org/10.1007/s11307-018-1252-5)

Wolf KI, Jha A, van Berkel A, Wild D, Janssen I, Millo CM, Janssen MJR, Gonzales MK, Timmers HJKM \& Pacak K 2019 Eruption of metastatic paraganglioma after successful therapy with 177Lu/90Y-DOTATOC and 177Lu-DOTATATE. Nuclear Medicine and Molecular Imaging 53 223-230. (https://doi.org/10.1007/s13139019-00579-w)

Wu Y, Pfeifer AK, Myschetzky R, Garbyal RS, Rasmussen P, Knigge U, Bzorek M, Kristensen MH \& Kjaer A 2013 Induction of anti-tumor immune responses by peptide receptor radionuclide therapy with (177)Lu-DOTATATE in a murine model of a human neuroendocrine tumor. Diagnostics 3 344-355. (https://doi.org/10.3390/ diagnostics3040344)

Yadav MP, Ballal S \& Bal C 2019 Concomitant (177)Lu-DOTATATE and capecitabine therapy in malignant paragangliomas. EJNMMI Research 9 13. (https://doi.org/10.1186/s13550-019-0484-y)

Yordanova A, Mayer K, Brossart P, Gonzalez-Carmona MA, Strassburg CP, Essler M \& Ahmadzadehfar H 2017 Safety of multiple repeated cycles of (177)Lu-octreotate in patients with recurrent neuroendocrine tumour. European Journal of Nuclear Medicine \& Molecular Imaging 44 1207-1214. (https://doi.org/10.1007/s00259-017-3652-1)

Yordanova A, Wicharz MM, Mayer K, Brossart P, Gonzalez-Carmona MA, Strassburg CP, Fimmers R, Essler M \& Ahmadzadehfar H 2018 The role of adding somatostatin analogues to peptide receptor radionuclide therapy as a combination and maintenance therapy. Clinical Cancer Research 24 4672-4679. (https://doi. org/10.1158/1078-0432.CCR-18-0947)

Zandee WT, Feelders RA, Smit Duijzentkunst D, Hofland J, Metselaar RM, Oldenburg RA, van Linge A, Kam BLR, Teunissen J, Korpershoek E, et al. 2019 Treatment of inoperable or metastatic paragangliomas and pheochromocytomas with peptide receptor radionuclide therapy using 177Lu-DOTATATE. European Journal of Endocrinology 181 45-53. (https://doi.org/10.1530/EJE-18-0901)

Zelinka T, Timmers HJ, Kozupa A, Chen CC, Carrasquillo JA, Reynolds JC, Ling A, Eisenhofer G, Lazurova I, Adams KT, et al. 2008 Role of positron emission tomography and bone scintigraphy in the evaluation of bone involvement in metastatic pheochromocytoma and paraganglioma: specific implications for succinate dehydrogenase enzyme subunit B gene mutations. Endocrine-Related Cancer 15 311-323. (https://doi.org/10.1677/ ERC-07-0217)

Zhang J, Wang H, Jacobson O, Cheng Y, Niu G, Li F, Bai C, Zhu Z \& Chen X 2018 Safety, pharmacokinetics, and dosimetry of a longacting radiolabeled somatostatin analog (177)Lu-DOTA-EB-TATE in patients with advanced metastatic neuroendocrine tumors. Journal of Nuclear Medicine 59 1699-1705. (https://doi.org/10.2967/ jnumed.118.209841)

Zhuang Z, Yang C, Lorenzo F, Merino M, Fojo T, Kebebew E, Popovic V, Stratakis CA, Prchal JT \& Pacak K 2012 Somatic HIF2A gain-offunction mutations in paraganglioma with polycythemia. New England Journal of Medicine 367 922-930. (https://doi.org/10.1056/ NEJMoa1205119)

Zovato S, Kumanova A, Dematte S, Sansovini M, Bodei L, Di Sarra D, Casagranda E, Severi S, Ambrosetti A, Schiavi F, et al. 2012 Peptide receptor radionuclide therapy (PRRT) with 177Lu-DOTATATE in individuals with neck or mediastinal paraganglioma (PGL). Hormone and Metabolic Research 44 411-414. (https://doi. org/10.1055/s-0032-1311637) https://erc.bioscientifica.com https://doi.org/10.1530/ERC-19-0165 (c) 2019 Society for Endocrinology Published by Bioscientifica Ltd. Printed in Great Britain
Received in final form 9 September 2019

Accepted 12 September 2019

Accepted Preprint published online 12 September 2019 